\title{
Biofuels
}

\section{Gasoline pre-blending processes for efficient ethanol recovery: effects of process parameters and process modifications for improved performance --Manuscript Draft--}

\begin{tabular}{|l|l|}
\hline Full Title: & $\begin{array}{l}\text { Gasoline pre-blending processes for efficient ethanol recovery: effects of process } \\
\text { parameters and process modifications for improved performance }\end{array}$ \\
\hline Manuscript Number: & TBFU-2018-0259 \\
\hline Article Type: & Original Article \\
\hline Keywords: & Bio-fuels; Ethanol; Process Design; Energy; Fuel \\
\hline Abstract: & $\begin{array}{l}\text { With over twenty billion gallons of bio-ethanol produced annually, optimization of bio- } \\
\text { ethanol production processes is a major priority for sustainability research. Recent } \\
\text { research has made great strides toward improving the efficiency of bio-ethanol } \\
\text { production through the development of gasoline pre-blending processes which use } \\
\text { liquid-liquid phase separation to eliminate excess water with minimal energy input. This } \\
\text { paper investigates the effects of process parameters on the performance and } \\
\text { efficiency of this class of process, offering a design basis for engineers developing new } \\
\text { processes along with a broader understanding of their potential performance and } \\
\text { economic value. Also explored are a range of process modifications capable of } \\
\text { improving process performance. It has been found that Blending Ratio and initial } \\
\text { alcohol concentration are the key parameters in determining ethanol recovery, with the } \\
\text { number of liquid-liquid contact stages and the temperature also being significant. It has } \\
\text { also been shown that temperature-swing decanting can significantly improve alcohol } \\
\text { recovery, reducing ethanol losses by as much as 33\% in a typical gasoline pre- } \\
\text { blending setup. }\end{array}$ \\
\hline
\end{tabular}




\title{
Gasoline pre-blending processes for efficient ethanol recovery: effects of process parameters and process modifications for improved performance
}

\author{
Neil Stacey*a, María J. Fernández-Torres, ${ }^{\mathrm{a}, \mathrm{b}}$ and David Glasser ${ }^{\mathrm{a}}$ \\ a Institute for the Development of Energy for African Sustainability (IDEAS), College of Science, \\ Engineering and Technology, University of South Africa (UNISA), c/o Christiaan de Wet \& Pioneer \\ Avenue, Florida Campus 1710, Johannesburg (South Africa) \\ ${ }^{b}$ Permanent address: Departamento de Ingeniería Química, University of Alicante, Apartado 99 \\ E-03080 (Spain), Tel: (+34)965903867, Fax: (+34) 965903826. \\ *Corresponding Author: e-mail: stacey.neil@gmail.com
}

\begin{abstract}
With over twenty billion gallons of bio-ethanol produced annually, optimization of bio-ethanol production processes is a major priority for sustainability research. Recent research has made great strides toward improving the efficiency of bio-ethanol production through the development of gasoline pre-blending processes which use liquid-liquid phase separation to eliminate excess water with minimal energy input. This paper investigates the effects of process parameters on the performance and efficiency of this class of process, offering a design basis for engineers developing new processes along with a broader understanding of their potential performance and economic value. Also explored are a range of process modifications capable of improving process performance. It has been found that Blending Ratio and initial alcohol concentration are the key parameters in determining ethanol recovery, with the number of liquid-liquid contact stages and the temperature also being significant. It has also been shown that temperature-swing decanting can significantly improve alcohol recovery, reducing ethanol losses by as much as $33 \%$ in a typical gasoline pre-blending setup.
\end{abstract}

\section{Introduction}

Transportation accounts for over a quarter of all $\mathrm{CO}_{2}$ emissions, and is therefore a priority area for sustainability research and environmental legislation, with increasingly strict regulation on fuels. For this reason, many countries are adopting mandatory blending of biofuels. Biofuels and their blends with fossil fuels are seen as cleaner energy sources because they are partially produced from renewable feed-stocks, reducing net carbon emissions [1]-[3]. A blend in this context is prepared mixing two or more compatible petroleum products where at least one of them is a biofuel. The goal of most of this legislation is to minimize damage to the climate and to human health. Harmful combustion by-products can include $\mathrm{CO}$, NOx and PAHs (polycyclic aromatic hydrocarbons) unburned hydrocarbons and particulate matter [4], [5]. Such pollutants affect air quality, especially in urban contexts. 
Different chemical substances have been tried as alternative for blending with gasoline. Ethanol is one of the most widely used renewable fuels for internal combustion engines [1], [5]. Considerable research has been conducted on the properties of ethanol as a fuel additive. For instance, [4] studied the characteristics and reactivity of soot particles from ethanolgasoline blends. [5] studied the blending of ethanol with gasoline in increasing ratios of ethanol (10, 20 and $30 \% \mathrm{vol})$ and its effect in engine design. [6] studied the octane numbers of ethanol blends. [7] studied different combustion chamber geometries in spark ignition engines fueled with ethanol and gasoline blends, etc. Considerable research has also been conducted on the energy efficiency of the process of bio-ethanol production for use in fuel [2], [8], [9]. Particular focus has been placed on optimizing the process to improve its energy efficiency, thereby reducing its carbon footprint and increasing its profitability.

A new approach to the process has been proposed, whereby ethanol is blended with gasoline without having first been fully purified, thereby exploiting liquid phase separation to conveniently eliminate the remainder of the water, as shown in Fig 1 [9], [10]. The mixture naturally splits into two phases which can be separated by means of one or more mixersettlers. In other words, the same phase split which makes water a problematic impurity in gasoline could be exploited to facilitate an energy-efficient separation; blending of water and gasoline results in the formation of two separate liquid phases without the addition of any separation energy. This process is called "gasoline pre-blending" because it does not need to fully eliminate the water prior to blending. If the design of the phase split is done correctly, the gasoline acquires the desired amount of ethanol, resulting in a suitable fuel mixture. According to this same author [9], [11], the overall process shown in Fig.1 results in more efficient separation of bioethanol from fermentation products, with significant energy and cost savings.

However, this class of processes has not yet been subject to detailed research or optimization, leaving considerable scope for improvement of the specific process shown in Fig 1, as well as the development of new processes using the concept of gasoline pre-blending.

This paper examines the effects of different variables: temperature, blending ratio (see section 2), number of mixer-settler units, water content in feed ethanol etc., on the performance and efficiency of gasoline pre-blending processes. This study serves to further explore the performance limits of this promising new class of processes, as well as to inform their design in an industrial context. It also examines process modifications that offer clear performance benefits, further improving the efficiency of ethanol production processes. 


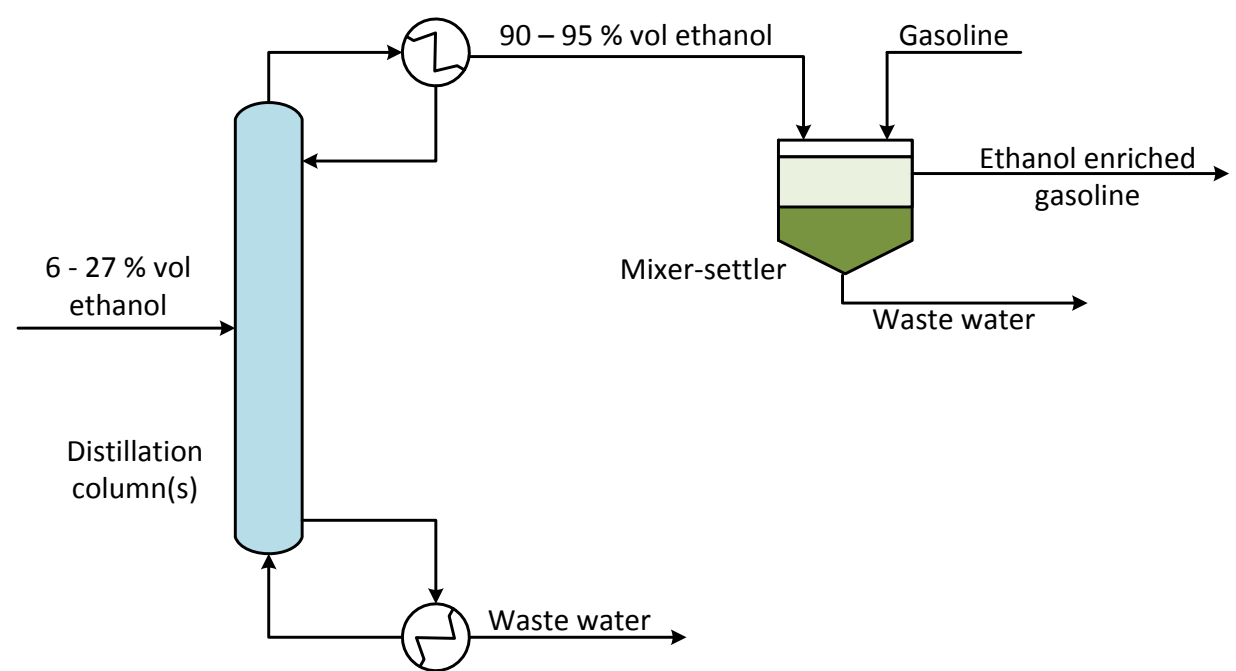

Fig 1. Overall process flowsheet for efficient bioethanol separation using ethanol pre-blending.

\section{Definitions and Methodology}

We need to define two parameters that will be used frequently in this research: recovery and blending ratio. Recovery is the fraction of alcohol/s (in this research ethanol) from the feed aqueous stream that ends up in the fuel phase. Blending ratio (BR) is the volume of gasoline fed to the liquid-liquid extraction unit(s) divided by the volume of (pure) ethanol in the aqueous stream fed to the same unit(s). The blending ratio must be selected based on the desired ethanol content in the fuel product and it can be more or less determined as soon as a product specification is selected which depends on the country. At present, the US legislations predominantly uses a $10 \%$ in volume blend of ethanol in gasoline. In South Africa, legislation mandates blends containing $2 \%$ ethanol. Hence, $10 \%$ and $2 \%$ blends are the targets in this paper firstly because they offer solutions for those two scenarios and secondly, because they offer a broad range of compositions, leading to results that can be considered qualitatively valid for compositions inside that range.

In order to be able to compare different situations, we would need abundant liquid-liquid equilibrium (LLE) data for the ternary mixture of water-ethanol-gasoline at different temperatures. Unfortunately, the exact composition of gasoline is variable since different brands have proprietary fuel additives and dyes. Furthermore, the composition of gasoline changes with time and location since technology and legislation evolve. As a result, no gasoline composition can be considered universal. This fact is expected to influence the phase equilibrium results and the outcomes of this research. We have circumvented this problem by choosing a reasonable stand-in for gasoline for the purpose of preliminary design: isooctane [9], [12] and achieve our goals with simulations in Aspen to model the phase equilibrium at different conditions. The results with isooctane can be extrapolated to particular gasoline blends since it provides a universal basis for design. The UNIQUAC model was selected for this purpose, using ASPEN's inbuilt parameters. The accuracy of this approach is somewhat debatable and the use of a fitted model is preferable where available but in the absence of gasoline-specific data at a range of temperatures, it becomes sensible to use the in-built modelling of a commercial package, which can be assumed to be sufficiently accurate for determining qualitative trends. For all these reasons, the results shown in this paper must be considered to be qualitative 
descriptions rather than exacting quantitative predictions. Actual process performance will vary considerably depending on a multitude of factors affecting fuel mix and stability. The results presented here are intended to serve as a baseline for preliminary design, from which a designer can extrapolate using the specific properties of the appropriate fuel mix for their context.

The different factors that we have tested are: blending ratio, temperature, number of mixingsettling units and water content on feed ethanol.

\section{Results}

The different results are grouped according to the main parameter analyzed. All numerical data obtained for this research are presented in detail in the supplementary data.

\subsection{Blending ratios}

The effects of blending ratio at atmospheric conditions and at $25 \circ \mathrm{C}$ with different number of units for mixing-settling (or stages) are presented in Fig.2. The ethanol content in the feed stream is $95 \%$ vol in all cases studied. Three different scenarios have been examined: 1-stage of mixing settling unit, 2-stages of mixing settling units and 16-stages. Fig. 2 shows two different parameters in the two $y$-axes plotted: recovery and volumetric percentage of ethanol in the fuel blend exit product.

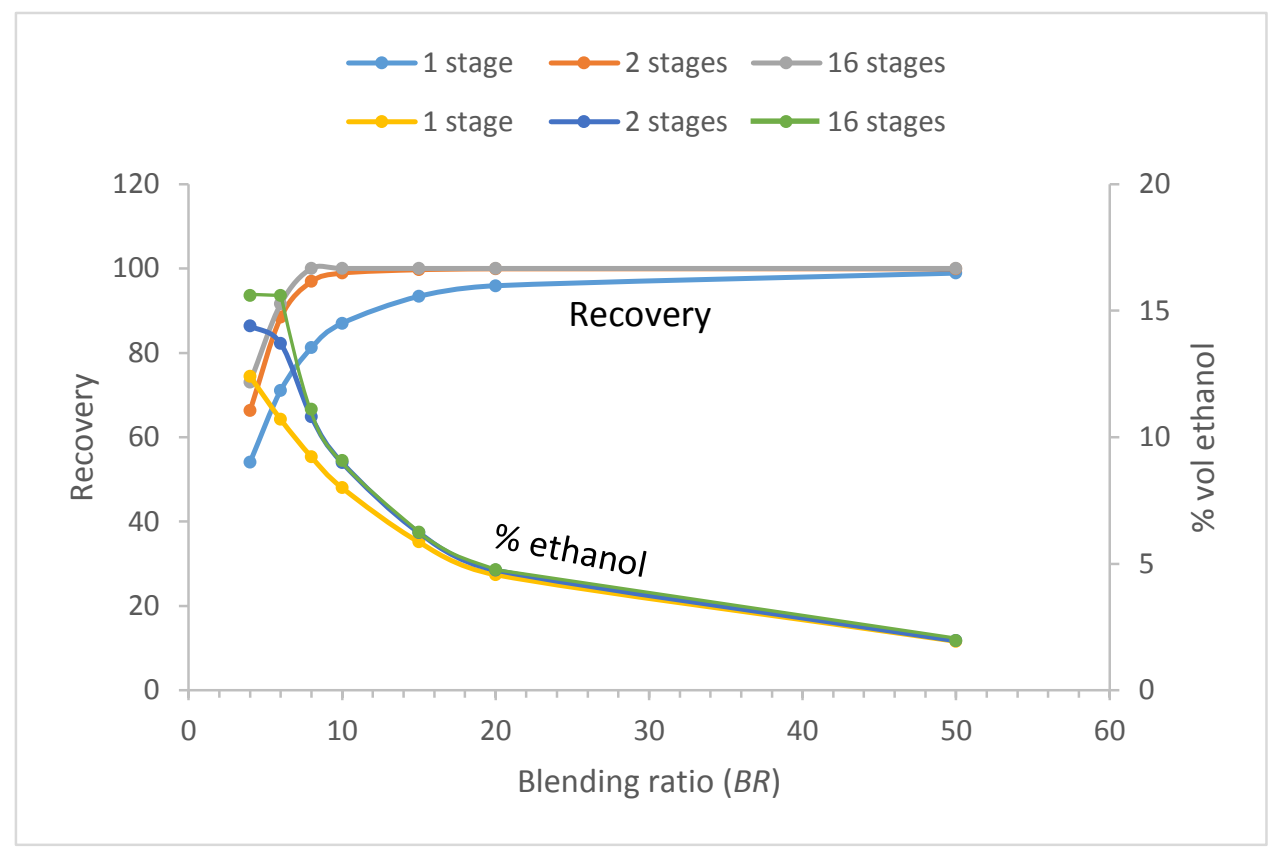

Fig 2. Effect of blending ratio in recovery and in the content of ethanol in the gasoline product at 25ㄷ.

Fig. 2 demonstrates the expected result that higher blending ratios (which will yield gasoline mixtures with low content of alcohol) result in higher recovery of ethanol. For the 16-stage process, complete recovery of ethanol occurs for all blending ratios 8 and above, indicating that for that case there is no benefit increasing the blending ratio above 8, except perhaps for dealing with initial ethanol content lower than the 95\% assumed here. A two-stage process with blending ratio in the 8-10 range offers the desirable ethanol content along with almost complete 
recovery. The multistage process with blending ratios in this range also achieves the desired composition, but with complete recovery of ethanol. This is quite likely the most desirable starting point for designing a process where the final product must be a $10 \%$ vol of ethanol.

It must be noted that the $2 \%$ ethanol blend required by South African law is easily obtained with a high recovery of ethanol. Even the single-stage process can achieve recovery of $98.9 \%$ for an ethanol content of $1.94 \%$. The 2 -stage process offers higher recoveries, approaching complete recovery for high blending ratios.

This has several implications for this process in the South African context. Firstly, a two-stage process will likely be adequate, giving designers the option of minimizing process complexity and capital cost while still achieving good process performance. Secondly, the multi-stage process so easily accomplishes what is necessary that it can be inferred that it may be possible to achieve a satisfactory performance when beginning with an ethanol mixture more dilute than the $95 \%$ studied here. This possibility is examined in section 3.4 .

\subsection{Temperature}

Temperature can be expected to have a profound impact on phase equilibrium and consequently on process performance. From section 3.1, we conclude that it seems reasonable to concentrate our research on a process with only 2 stages of mixer-settlers to obtain a good ethanol recovery for most blending ratios. Therefore, the basic flowsheet for the remainder of this paper is the one depicted in Fig. 3 with small variations that we shall see.

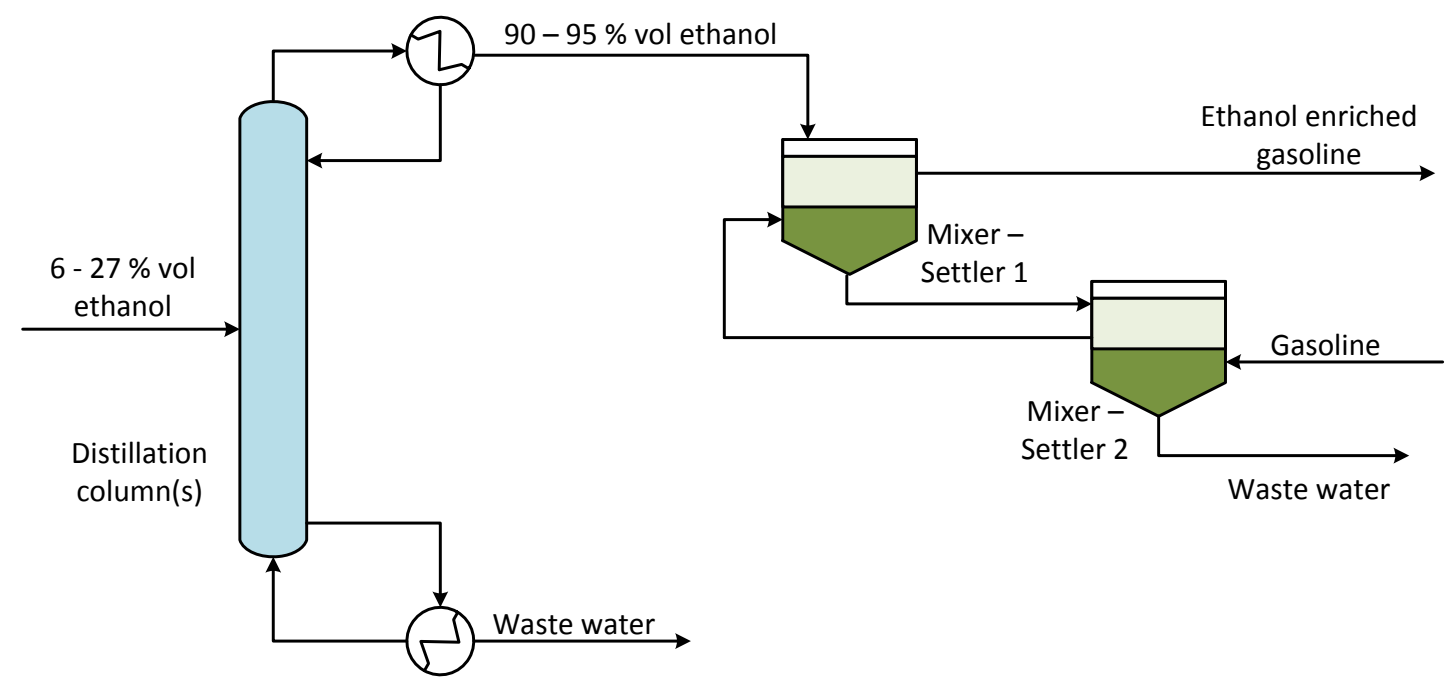

Fig. 3. Flowsheet with 2 stages of mixing-settling for enriching gasoline with alcohol from fermentation.

Also, from the results shown in section 3.1 we will study temperature effect for a $B R$ (blending ratio) at around 8 . Therefore, the effects of temperature on a two-stage blending process at $B R$ of 6 and 8 are simulated and the results shown in Fig.4. It is clear that temperature has a significant impact on the results. High-temperature phase-splits offer increased ethanol content and recovery but at the cost of higher water content that can reduce the stability of the blended gasoline. Stability in this context is understood as a possible phase-split (gasoline/water) happening inside the car tank. Lower temperature saturated mixtures have significantly lower water content than saturated mixtures at higher temperatures. This means that a mixture that is saturated at a high temperature will become unstable if the temperature is lowered, and that 
a mixture that is saturated at a low temperature (below ambient conditions) will be undersaturated and highly stable at ambient conditions.

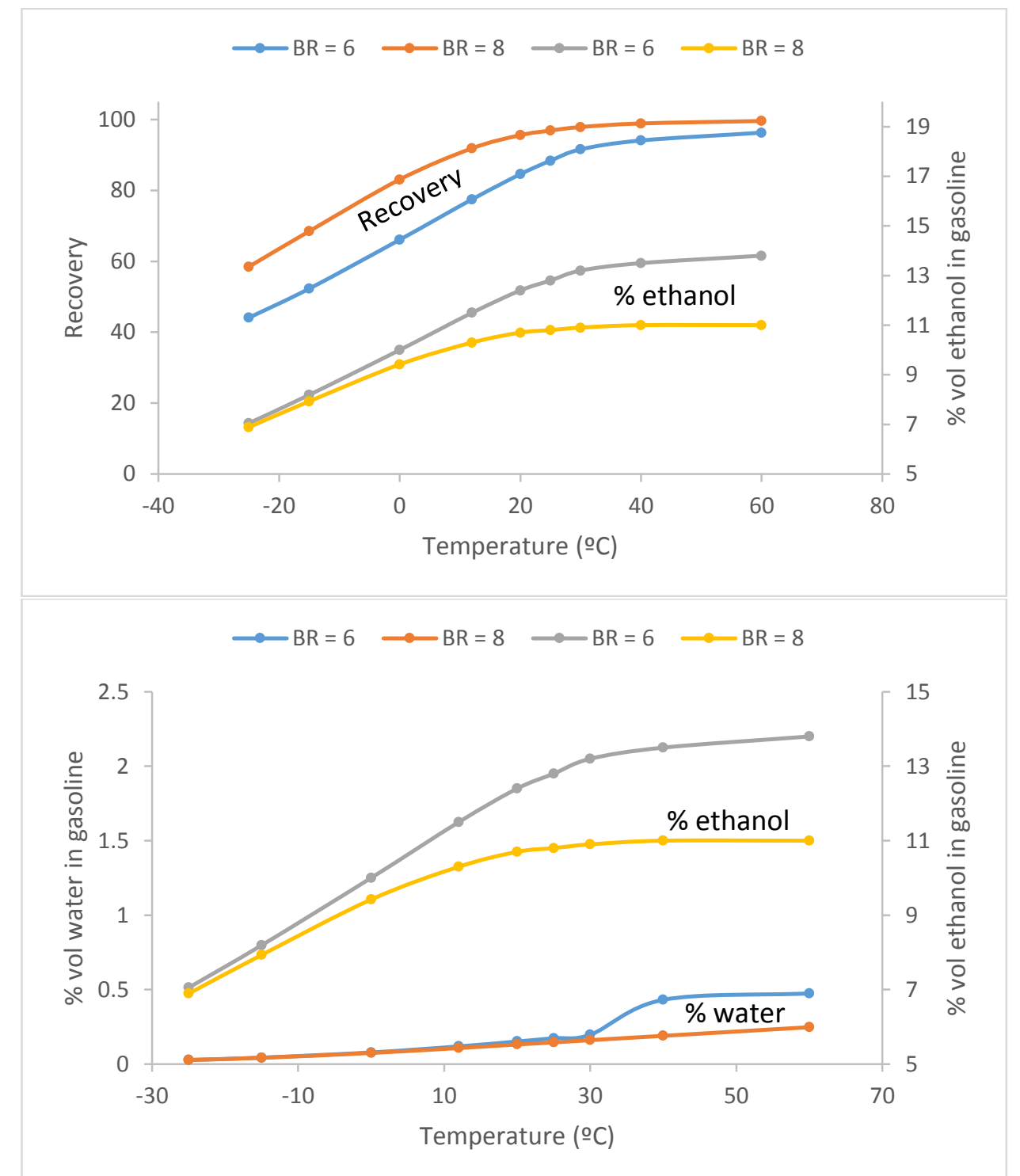

Fig 4. Effect of temperature on the recovery and percentages of ethanol (top) and water (bottom) in the gasoline product.

Low temperature phase-splits offer significantly more stable mixtures but this stability improvement is offset somewhat by the reduced ethanol content, which limits the possibility for stabilization through the blending of additional petrol. This, combined with the significant reduction in ethanol recovery and the general expense and impracticality of large-scale cryogenic processes suggests that these very low temperature processes are economically unfeasible.

Fig. 5 shows the effect of temperature on one particular tie line, chosen as an example. The 3 tie-lines correspond to the same heterogeneous mixture $(11.0 \%$ vol ethanol, $0.58 \%$ vol water, $88.4 \%$ vol isooctane). This information is taken from Fig.4 $(B R=8)$ and is fully documented in the Supplementary Material section. As the temperature increases, the content of ethanol in the aqueous phase decreases dramatically, whereas the ethanol content in the organic phase increases, although not much. It can be concluded that higher temperatures lead ethanol to favour the fuel phase more strongly, thereby improving the recovery of ethanol. 


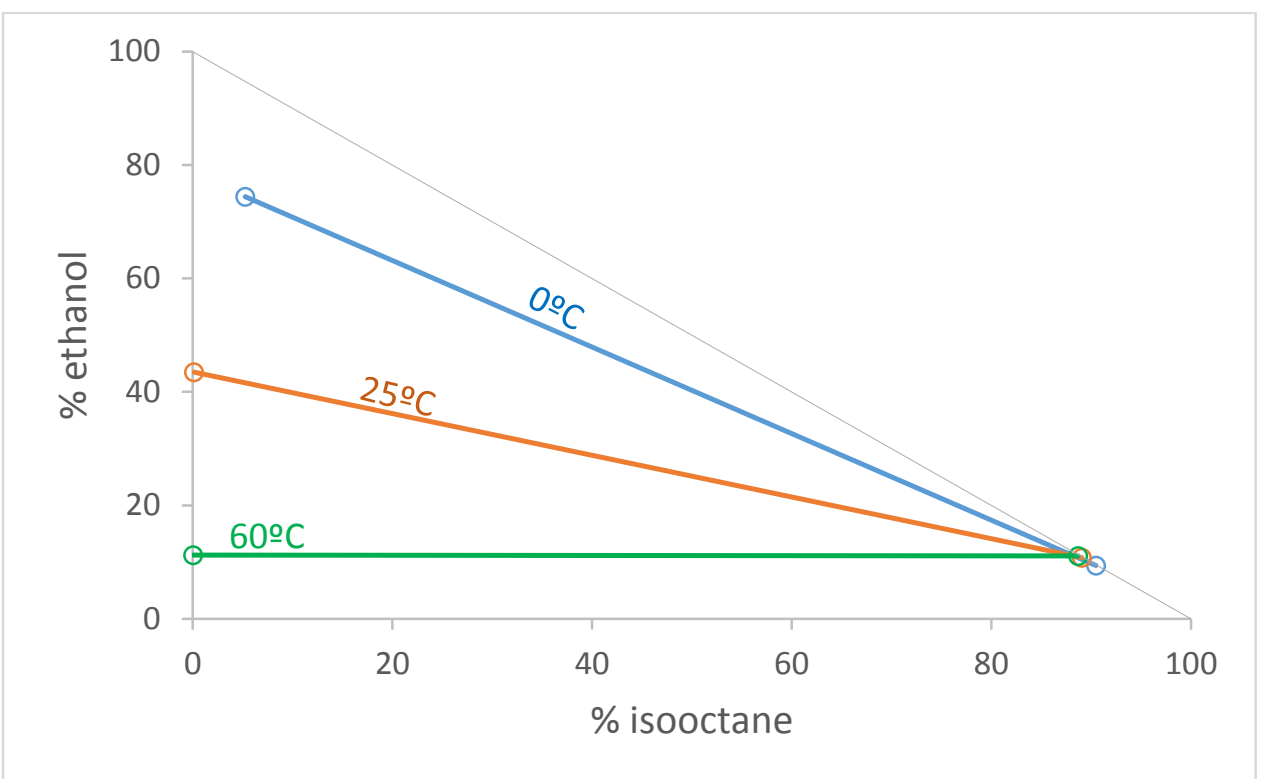

Fig 5. Effect of temperature on the tie line developed from the same heterogeneous mixture: $11.4 \%$ vol ethanol, $0.58 \%$ vol water, $88.4 \%$ vol isooctane

One drawback of using higher-temperature phase splits is that they also result in a somewhat higher water content for the fuel phase. This means that a mixture that is saturated at a high temperature will be unstable at a lower temperature, and therefore not suitable for use as a fuel. Hence, a final decanting at a lower temperature would be needed in order to achieve a stable mixture. The specific details of a country's legislation will also impose different constraints on this final decanting. While some countries simply require a stable mixture, others specify a particular water content, regardless of stability, and those countries do not all specify the same thresholds. Hence, it is up to a designer to consider the particular context where a process will be implemented and adapt accordingly.

\subsection{Temperature Swing process}

From the results in the previous sections we conclude that a temperature-swing phase split is worth examining. This will imply that the initial liquid-liquid extraction takes place at high temperature (around $60^{\circ} \mathrm{C}$ ), resulting in a high recovery of ethanol. To eliminate the excess water and therefore improve stability for lower temperatures, this mixture could subsequently be decanted at one or two settlers at lower temperatures. This will result in adding one or two decanters to the flowsheet shown in Fig.3. The enhanced flowsheet is shown in Fig.6.

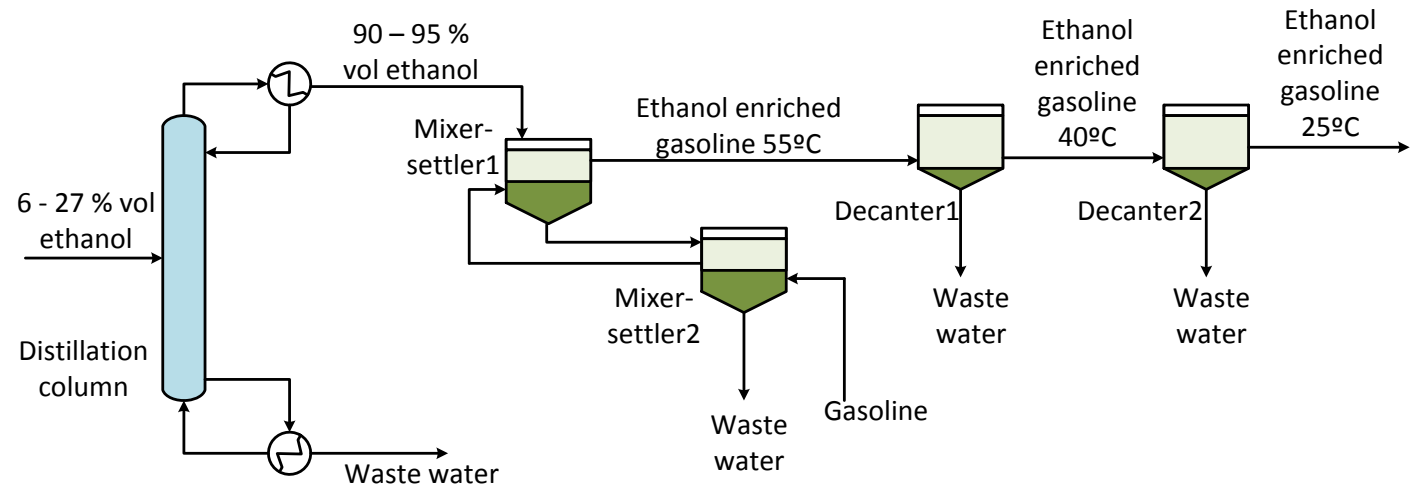

Fig 6. Flowsheet diagram where 2 extra decanters have been added to Fig.3. 
In Fig. 6 it can be seen that blending occurs at high temperature. This is relatively easy to achieve since the overhead stream from the distillation column will be at high temperature and gasoline can be preheated with residual heat from the reboiler. The heterogeneous mixtures contain a small amount of water, because the ethanol is provided with relatively high purity. For this reason, the split aqueous phase cannot take with it much ethanol, despite that the tie lines reveal that water solubilizes ethanol better than isooctane.

The experiments conducted in this section assess the temperature swing proposed in Fig.6. The intention is to obtain a hydrocarbon product of the same stability as the one obtained at ambient temperature according to the flowsheet shown in Fig.3, and hopefully with a higher recovery of ethanol. Fig. 7 and 8 offer the corresponding results of the simulation in Aspen. These figures show that an initial 2-stage phase separation at $55^{\circ} \mathrm{C}$ followed by decanting at ambient temperature ("2 stages +1 decanter") results in increased ethanol content and improved recovery when compared to the situation shown in Fig.3, particularly at low blending ratios. This result can be explained intuitively; as the temperature is lowered, water and gasoline become less and less miscible, so water is removed as temperature is dropped. Doing this at a series of staged temperatures instead of at a single low temperature minimizes the ethanol that is lost into the water phase as this occurs. The process situation depicted in Fig.6, i.e., "2-stages +2 decanters" with initial phase separation at $55^{\circ} \mathrm{C}$ and subsequent decanting at $40^{\circ} \mathrm{C}$ and $25^{\circ} \mathrm{C}$ results in not so much improvement if it is compared to the case of "2-stages +1 decanters" but it does improve if it is compared to the situation in Fig.3.

To illustrate the latest, let's consider the process with a blending ratio of 10 . the "2-stages" (Fig.3) results in a fuel product with $8 \%$ vol ethanol content where $13 \%$ of the feed ethanol is lost in the water phase, while the "2-stages +2 decanters" results in an ethanol content of $8.37 \%$ with $8.6 \%$ of ethanol lost in the water phase. This translates to a reduction of ethanol losses of about $34 \%$. All these results prove that it is worth considering a temperature swing process as a means of improving recovery in gasoline pre-blending processes.

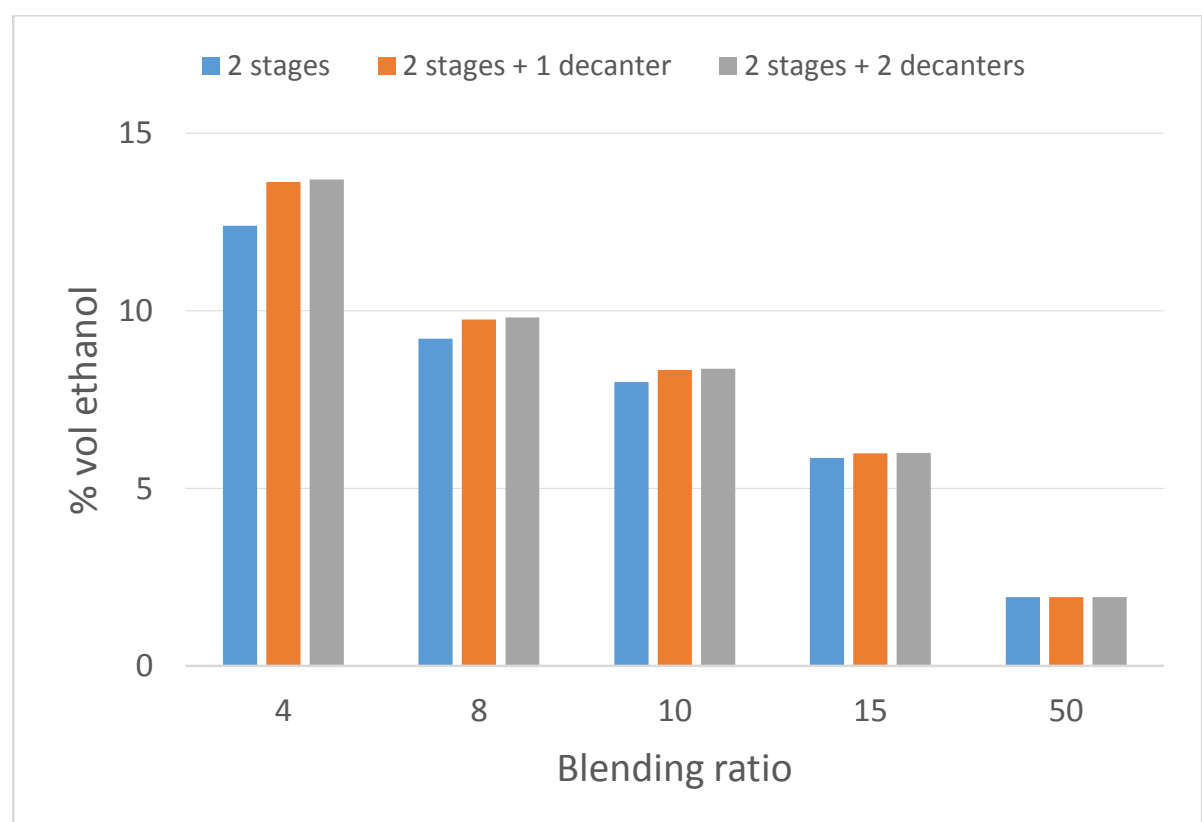

Fig 7. Effect of the temperature swing process on the volumetric percentage of ethanol at different blending ratios. "2 stages" corresponds to the situation depicted in Fig. 3 (both settlers at 25ㄷ). "2 stages + 1 decanter" corresponds 
to the situation in Fig. 6 but without decanter 1 (temperatures are 55ㄷ for the first and second mixer-settler and $25^{\circ} \mathrm{C}$ for the decanter2). "2 stages + 2 decanter" series corresponds to exactly Fig. 6.

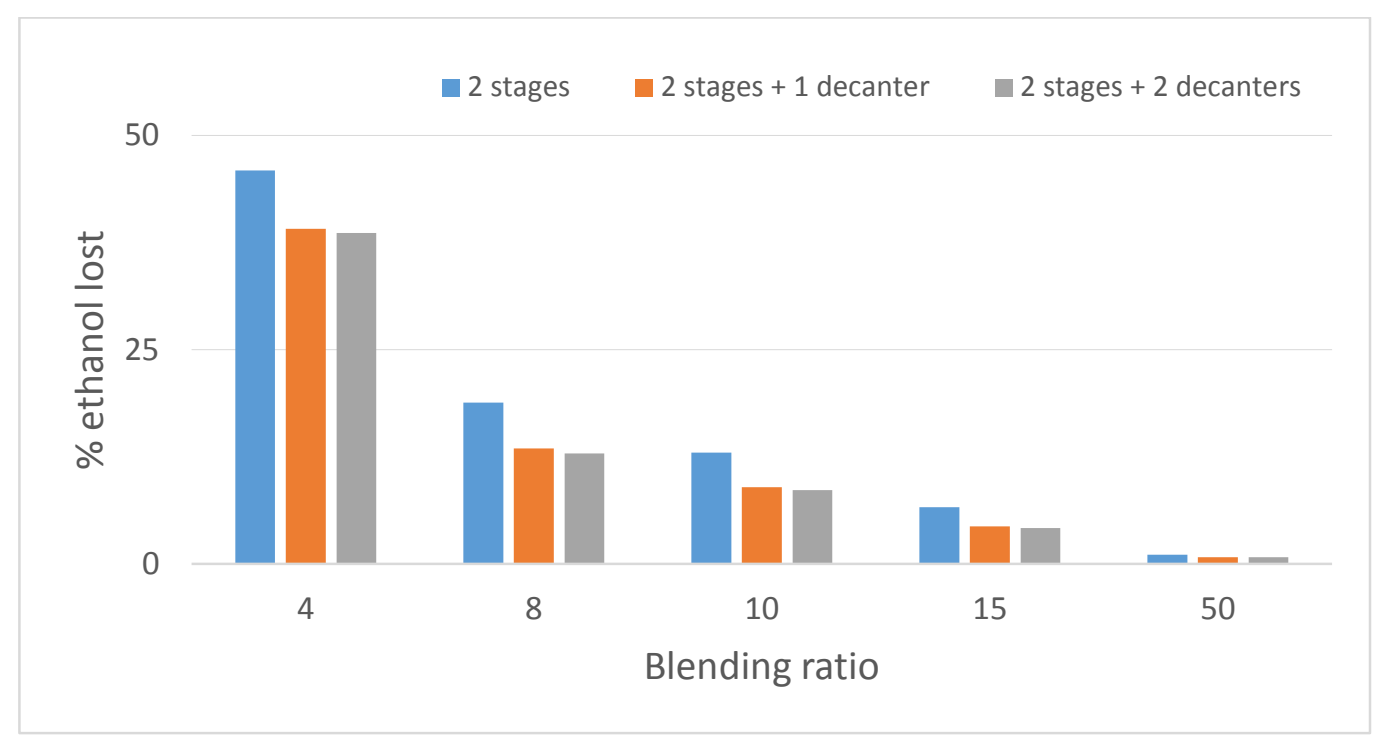

Fig 8. Effect of the temperature swing process on the \% of ethanol lost in the water phase (ethanol in aqueous stream / ethanol in feed stream $\times 100 \%$ ) at different blending ratios. " 2 stages" corresponds to the situation depicted in Fig. 3 (both settlers at 25ㅇ) . "2 stages +1 decanter" corresponds to the situation in Fig. 6 but without decanter 1 (temperatures are 55ㅇ for the first and second mixer-settler and 25ㅇ for the decanter 2 ). "2 stages +2 decanter" series corresponds to exactly Fig.6.

The logical extreme of this approach is to decant in a batch process where the aqueous phase is removed as it forms while the temperature is gradually lowered. The final decanting step need not be at ambient conditions; it could be conducted at a lower temperature in order to achieve improved stability while offsetting the performance reductions of low temperature phase separation.

\subsection{The effect of the content of water in the ethanol feed stream}

In this section we consider the effect of the water content in the ethanol stream. The $2 \%$ ethanol mixture required by South African law can be easily reached with high recovery using just single (Fig.1) or double stage (Fig.3) liquid-liquid extraction. This simplifies the process equipment required, but also suggests that a more challenging extraction from a stream with larger amount of water could be achieved using a multi-stage approach like that depicted in Fig.6. Starting with an ethanol composition lower than $95 \%$ would reduce the costs associated with the primary separation step and is therefore worth investigating in this case. We have explored three different scenarios: (a) an ethanol feed stream containing $85 \%$ vol in ethanol assessed in a process shown in Fig.3 at 25ㅇ; (b) an ethanol feed stream containing $50 \%$ vol in both, ethanol and water, also assessed in the process shown in Fig. 3 at $25{ }^{\circ} \mathrm{C}$ and (c) an ethanol feed stream containing $50 \%$ vol in both, ethanol and water, but assessed with the process shown in Fig. 6 . The results of this analysis is presented in Fig.10 and 11.

Fig.10 and 11 show that with an initial ethanol content of $85 \%$, the process remains viable for the South African context, since near-total recovery of ethanol still occurs at a blending ratio of 
50 while producing a fuel mixture with ethanol content close to the $2 \%$ required in SA. Purification to $85 \%$ can be presumed to be somewhat less costly than purifying to $95 \%$, so this result suggests another avenue of possible cost-saving and optimization. However, the lower ethanol content has a ruinous effect on the prospects of the process for the American or European contexts. With a starting ethanol content of $85 \%$, a two-stage process with a blending ratio of 4 recovers only $41.5 \%$ of ethanol, and doesn't even achieve $10 \%$ ethanol content. In other words, the more stringent requirements of the American/European context result in a process much more sensitive to starting ethanol content, whereas the South African context allows for a much more flexible process. In fact, beginning with an ethanol content of just $50 \%$ and using temperature swing decanting, a blending ratio of 40 results in a fuel mixture with ethanol content of $1.95 \%$, and ethanol recovery of $79.5 \%$.

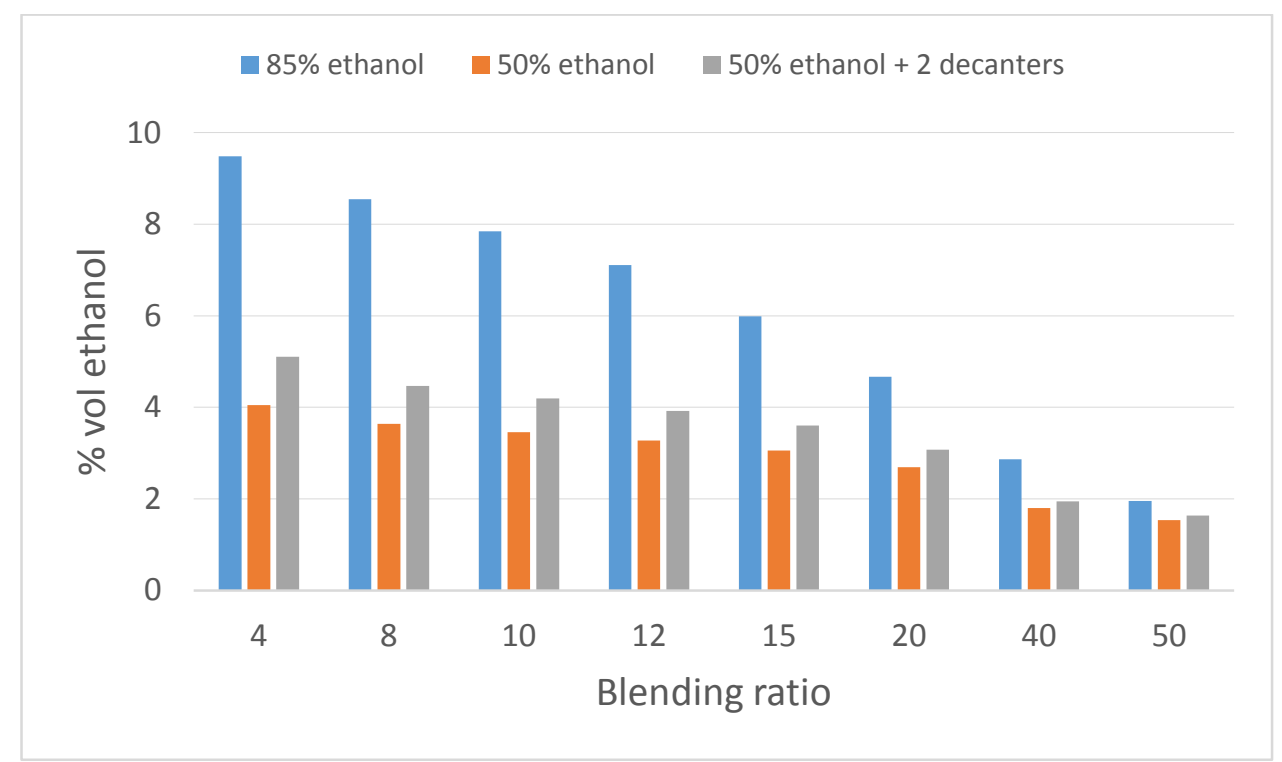

Fig 9. Effect of the amount of water in the feed ethanol stream for different BR on the \% of ethanol in the final product. Three different scenarios: (a) feed stream $85 \%$ vol ethanol in a process shown in Fig. 3 at 25ㄷ) (b) feed stream $50 \%$ vol ethanol in a process shown in Fig. 3 at $25 \circ$ C and (c) feed stream $50 \%$ vol ethanol in a process shown in Fig.6.

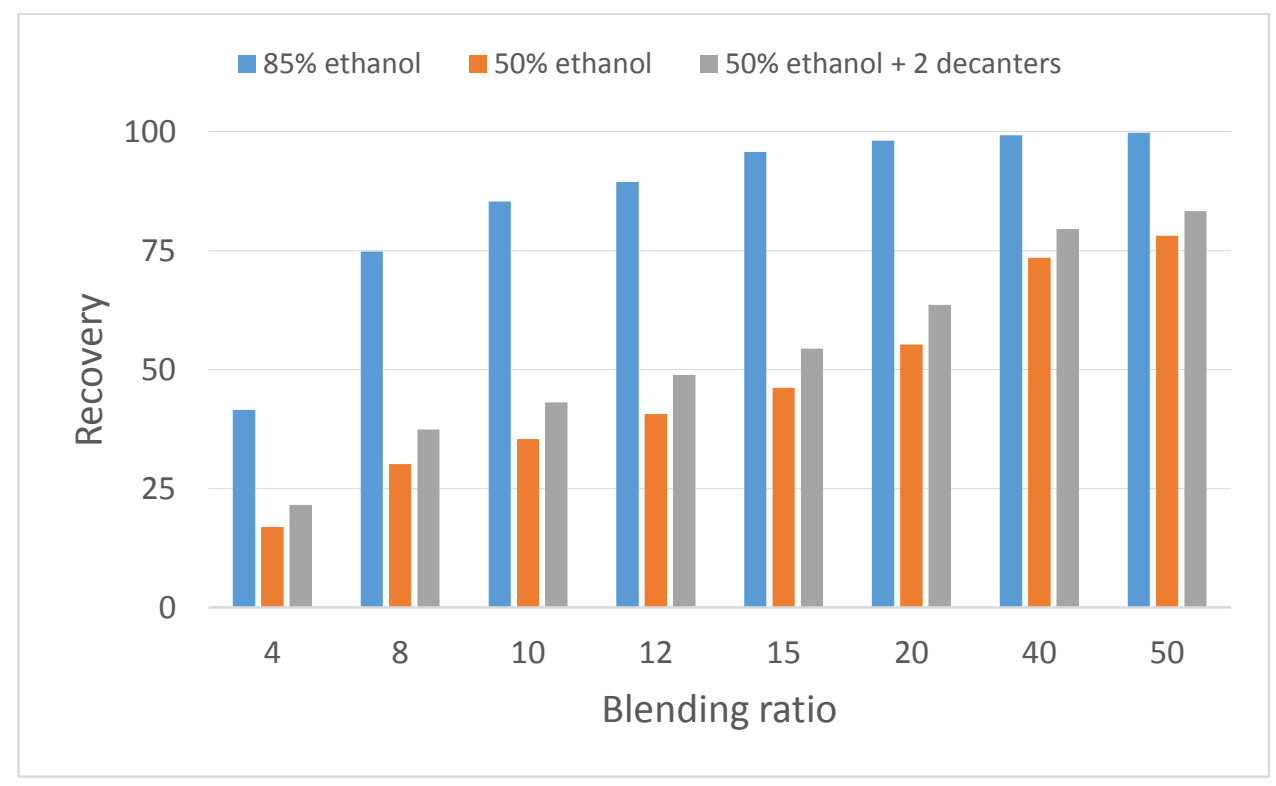


Fig 10. Effect of the amount of water in the feed ethanol stream for different BR on the recovery. Three different scenarios: (a) feed stream $85 \%$ vol ethanol in a process shown in Fig. 3 at 25ㄷ; (b) feed stream $50 \%$ vol ethanol in a process shown in Fig. 3 at $25 \circ \mathrm{C}$ and (c) feed stream 50\% vol ethanol in a process shown in Fig. 6.

Literature survey does not offer much by way of analysis of the energy requirements for distilling ethanol mixtures to this sort of composition, since it is not a step that is of particular interest in conventional processes to purify ethanol. However, it can be reasonably assumed that the energy requirements and capital cost investments required by such a process would be significantly below those involved in full purification, or even in purification to the azeotrope. It is up to designers to evaluate on a case-by-case basis whether or not the benefits of reduced separations costs are worth the reduced ethanol recovery, but this preliminary analysis indicates that it is a possibility worth considering.

\section{Conclusions}

In this research paper, the effects of design parameters have been examined in detail, yielding insights into the specific design decisions likely to optimize performance in any particular geographical context, and into the general thinking involved in developing and implementing phase-separation processes for bioethanol recovery, or for the recovery of other bio-fuels in similar processes.

Temperature, blending ratio and number of phase equilibrium stages have been identified as the main parameters affecting the performance of the phase separation process.

Higher temperatures result in higher ethanol content of the gasoline product and recovery, but stability is also linked to the temperature at which the final product is decanted. The temperature-swing decanting approach takes advantage of the improved ethanol recovery at higher temperatures without adversely affecting the stability of the final mixture. The step-wise decanting approach further improves process performance for the same reasons.

The blending ratio must be selected based on the desired ethanol content in the fuel product and is more or less determined as soon as a product specification is selected, excepting that there is some variation in the exact number insofar as other parameters affect the ethanol recovery and content to some degree.

The ideal number of stages, on the other hand, is highly contextual and will depend on economic considerations. The cost and process complexity involved in multi-stage processes are particularly undesirable if a high number of blending facilities are used at end-points on the fuel distribution network. A decentralised approach is ideal for limiting the financial impact of the corrosive effects of water, so this factor must be balanced against the economies of scale of central processing. In cases where a one- or two-stage process is able to achieve a desirable recovery and ethanol content, a decentralised approach becomes more viable.

In the South African context, the ideal approach is probably one where two-stage phaseseparation is carried out at a number of locations near the end-points of a fuel distribution network. Reaching the azeotrope in the initial separation is not necessary if the required ethanol content is $2 \%$, as in the South African context, and the most economical approach will likely be to reduce the cost of that initial separation by using a mixture with purity somewhat below the azeotrope.

The more stringent requirements of the US context places a strict constraint on the starting ethanol content; even with considerable process modification, processes beginning with reduced ethanol content cannot achieve adequate recovery of ethanol along with the $10 \%$ ethanol required in that context. The difficulty of achieving this high ethanol content also makes this process highly sensitive to any other factor affecting performance and it can thus be expected that in the US context, gasoline pre-blending processes must necessarily be somewhat over-designed in order to reliably achieve recovery targets. Hence, it is suggested that this be 
achieved through the use of multi-stage pre-blending processes. It has also been found in this paper that temperature step-down decanting can significantly improve ethanol recovery and should therefore be strongly advised for contexts where performance requirements are particularly stringent.

\section{Acknowledgements}

Dr M.J. Fernandez-Torres thanks the visiting researcher program, at the University of South Africa, for financial support.

\section{REFERENCES}

[1] A. DEMIRBAŞ, "Bioethanol from Cellulosic Materials: A Renewable Motor Fuel from Biomass," Energy Sources, vol. 27, no. 4, pp. 327-337, Feb. 2005.

[2] J. Goldemberg, "Ethanol for a Sustainable Energy Future," Science, vol. 315, no. 5813, pp. 808-810, Feb. 2007.

[3] Y. Lin and S. Tanaka, "Ethanol fermentation from biomass resources: current state and prospects," Appl. Microbiol. Biotechnol., vol. 69, no. 6, pp. 627-642, Feb. 2006.

[4] G. D. J. Guerrero Peña, Y. A. Hammid, A. Raj, S. Stephen, T. Anjana, and V. Balasubramanian, "On the characteristics and reactivity of soot particles from ethanolgasoline and 2,5-dimethylfuran-gasoline blends," Fuel, vol. 222, pp. 42-55, Jun. 2018.

[5] P. lodice, G. Langella, and A. Amoresano, "Ethanol in gasoline fuel blends: Effect on fuel consumption and engine out emissions of $\mathrm{SI}$ engines in cold operating conditions," Appl. Therm. Eng., vol. 130, Nov. 2017.

[6] J. Badra, A. S. AlRamadan, and M. Sarathy, "Optimization of the octane response of gasoline/ethanol blends," Jul. 2017.

[7] H. Al-Rawashdeh, "Impact of changing combustion chamber geometry on emissions, and combustion characteristics of a single cylinder SI (spark ignition) engine fueled with ethanol/gasoline blends," Jun. 2018.

[8] A. E. Farrell, R. J. Plevin, B. T. Turner, A. D. Jones, M. O'Hare, and D. M. Kammen, "Ethanol can contribute to energy and environmental goals," Science, vol. 311, no. 5760, pp. 506-508, Jan. 2006.

[9] N. T. Stacey, A. Hadjitheodorou, and D. Glasser, "Gasoline Preblending for EnergyEfficient Bioethanol Recovery," Energy Fuels, vol. 30, no. 10, pp. 8286-8291, Oct. 2016.

[10] A. Singh and G. P. Rangaiah, "Review of Technological Advances in Bioethanol Recovery and Dehydration," Ind. Eng. Chem. Res., vol. 56, no. 18, pp. 5147-5163, May 2017.

[11] N. T. Stacey, "Alternatives to distillation: multi-membrane permeation and petrol preblending for bio-ethanol recovery," Thesis, 2016.

[12] M. Rahman, M. Asadullah, M. Rahman, M. Nabi, and M. Azad, "Extraction of Gasohol Grade Ethanol from Aqueous Solution using Gasoline as Solvent," Bangladesh J. Sci. Ind. Res., vol. 42, no. 3, Feb. 2008. 
Gasoline pre-blending processes for efficient ethanol recovery: effects of process parameters and process modifications for improved performance

Neil Stacey*a, María J. Fernández-Torres, ${ }^{\mathrm{a}, \mathrm{b}}$ and David Glasser ${ }^{\mathrm{a}}$

a Institute for the Development of Energy for African Sustainability (IDEAS), College of Science, Engineering and Technology, University of South Africa (UNISA), c/o Christiaan de Wet \& Pioneer Avenue, Florida Campus 1710, Johannesburg (South Africa)

${ }^{b}$ Permanent address: Departamento de Ingeniería Química, University of Alicante, Apartado 99 E03080 (Spain), Tel: (+34)965903867, Fax: (+34) 965903826.

* Corresponding Author: e-mail: stacey.neil@gmail.com 
Gasoline pre-blending processes for efficient ethanol recovery: effects of process parameters and process modifications for improved performance

Neil Stacey*a , María J. Fernández-Torres, ${ }^{\mathrm{a}, \mathrm{b}}$ and David Glasser ${ }^{\mathrm{a}}$

\section{Supplementary Material: Raw stream data}

Table SM-1: Raw stream data for blending ratio analysis

\begin{tabular}{|c|c|c|c|c|c|c|}
\hline $\begin{array}{c}\text { number of } \\
\text { stages }\end{array}$ & $\begin{array}{c}\text { blending } \\
\text { ratio }\end{array}$ & component & $\begin{array}{l}\text { aqueous } \\
\text { feed } \\
\text { flowrate }\end{array}$ & $\begin{array}{l}\text { hydrocarbon } \\
\text { feed flowrate }\end{array}$ & $\begin{array}{c}\text { hydrocarbon } \\
\text { outlet flowrate }\end{array}$ & $\begin{array}{l}\text { aqeous outlet } \\
\text { flowrate }\end{array}$ \\
\hline \multirow[t]{3}{*}{1} & 4 & ETHANOL & 0.95 & & 0.51368824 & 0.43631189 \\
\hline & & WATER & 0.05 & & 0.00748227 & 0.04251774 \\
\hline & & C8H18-01 & 0 & 3.8 & 3.63038762 & 0.16961185 \\
\hline \multirow[t]{3}{*}{1} & 6 & ETHANOL & 0.95 & & 0.67577919 & 0.27422082 \\
\hline & & WATER & 0.05 & & 0.00975274 & 0.04024725 \\
\hline & & C8H18-01 & 0 & 5.7 & 5.63897168 & 0.06102826 \\
\hline \multirow[t]{3}{*}{1} & 8 & ETHANOL & 0.95 & & 0.77116116 & 0.1788389 \\
\hline & & WATER & 0.05 & & 0.0109309 & 0.03906911 \\
\hline & & C8H18-01 & 0 & 7.6 & 7.57897951 & 0.02102011 \\
\hline \multirow[t]{3}{*}{1} & 10 & ETHANOL & 0.95 & & 0.82635647 & 0.12364353 \\
\hline & & WATER & 0.05 & & 0.01146611 & 0.03853388 \\
\hline & & C8H18-01 & 0 & 9.5 & 9.4924652 & 0.00753481 \\
\hline \multirow[t]{3}{*}{1} & 15 & ETHANOL & 0.95 & & 0.88772213 & 0.06227787 \\
\hline & & WATER & 0.05 & & 0.01175932 & 0.03824067 \\
\hline & & C8H18-01 & 0 & 14.25 & 14.2491232 & 0.00087686 \\
\hline \multirow[t]{3}{*}{1} & 20 & ETHANOL & 0.95 & & 0.91092272 & 0.03907727 \\
\hline & & WATER & 0.05 & & 0.0117539 & 0.03824607 \\
\hline & & C8H18-01 & 0 & 19 & 18.9998194 & 0.00018081 \\
\hline \multirow[t]{3}{*}{1} & 50 & ETHANOL & 0.95 & & 0.93913031 & 0.01086968 \\
\hline & & WATER & 0.05 & & 0.01289188 & 0.03710809 \\
\hline & & C8H18-01 & 0 & 47.5 & 47.4999965 & $3.77 \mathrm{E}-06$ \\
\hline \multirow[t]{3}{*}{2} & 4 & ETHANOL & 0.95 & 0 & 0.63 & 0.32 \\
\hline & & WATER & 0.05 & 0 & 0.01 & 0.04 \\
\hline & & $\mathrm{C} 8 \mathrm{H} 18-01$ & 0 & 3.8 & 3.72 & 0.08 \\
\hline \multirow[t]{3}{*}{2} & 6 & ETHANOL & 0.95 & 0 & 0.84 & 0.11 \\
\hline & & WATER & 0.05 & 0 & 0.01 & 0.04 \\
\hline & & $\mathrm{C} 8 \mathrm{H} 18-01$ & 0 & 5.7 & 5.69 & 0.01 \\
\hline
\end{tabular}




\begin{tabular}{|c|c|c|c|c|c|c|}
\hline 2 & 8 & ETHANOL & 0.95 & 0 & 0.92 & 0.03 \\
\hline & & WATER & 0.05 & 0 & 0.01 & 0.04 \\
\hline & & C8H18-01 & 0 & 7.5 & 7.50 & 0.00 \\
\hline \multirow[t]{3}{*}{2} & 10 & ETHANOL & 0.95 & 0 & 0.94 & 0.01 \\
\hline & & WATER & 0.05 & 0 & 0.01 & 0.04 \\
\hline & & C8H18-01 & 0 & 9.5 & 9.50 & 0.00 \\
\hline \multirow[t]{3}{*}{2} & 15 & ETHANOL & 0.95 & 0 & 0.95 & 0.00 \\
\hline & & WATER & 0.05 & 0 & 0.01 & 0.04 \\
\hline & & C8H18-01 & 0 & 14.25 & 0.00 & 14.25 \\
\hline \multirow[t]{3}{*}{2} & 20 & ETHANOL & 0.95 & 0 & 0.95 & 0.00 \\
\hline & & WATER & 0.05 & 0 & 0.01 & 0.04 \\
\hline & & C8H18-01 & 0 & 19 & 19.00 & 0.00 \\
\hline \multirow[t]{3}{*}{2} & 50 & ETHANOL & 0.95 & 0 & 0.00 & 0.95 \\
\hline & & WATER & 0.05 & 0 & 0.04 & 0.01 \\
\hline & & C8H18-01 & 0 & 47.5 & 0.00 & 47.50 \\
\hline \multirow[t]{3}{*}{16} & 4 & ETHANOL & 0.95 & 0 & 0.25627612 & 0.69372389 \\
\hline & & WATER & 0.05 & 0 & 0.04079378 & 0.00920621 \\
\hline & & C8H18-01 & 0 & 3.8 & $4.98 \mathrm{E}-02$ & 3.7502352 \\
\hline \multirow[t]{3}{*}{16} & 6 & ETHANOL & 0.95 & 0 & 7.96E-02 & 0.87040404 \\
\hline & & WATER & 0.05 & 0 & 0.03843498 & 0.01156501 \\
\hline & & C8H18-01 & 0 & 4.7 & 0.00189078 & 4.69810922 \\
\hline \multirow[t]{3}{*}{16} & 8 & ETHANOL & 0.95 & 0 & $3.68 \mathrm{E}-19$ & 0.95 \\
\hline & & WATER & 0.05 & 0 & 0.03722463 & 0.01277536 \\
\hline & & C8H18-01 & 0 & 7.6 & $1.19 \mathrm{E}-07$ & 7.59999988 \\
\hline \multirow[t]{3}{*}{16} & 10 & ETHANOL & 0.95 & $0.00 \mathrm{E}+00$ & $5.34 \mathrm{E}-21$ & 0.95 \\
\hline & & WATER & 0.05 & 0 & 0.03735459 & 0.0126454 \\
\hline & & C8H18-01 & 0 & 9.5 & $1.19 \mathrm{E}-07$ & 9.49999988 \\
\hline \multirow[t]{3}{*}{16} & 15 & ETHANOL & 0.95 & 0 & $5.93 \mathrm{E}-24$ & 0.95 \\
\hline & & WATER & 0.05 & 0 & 0.03787394 & 0.01212605 \\
\hline & & C8H18-01 & 0 & 14.25 & $1.21 \mathrm{E}-07$ & 14.2499999 \\
\hline \multirow[t]{3}{*}{16} & 20 & ETHANOL & 0.95 & 0 & $5.95 \mathrm{E}-26$ & 0.95 \\
\hline & & WATER & 0.05 & 0 & 0.03816652 & $1.18 \mathrm{E}-02$ \\
\hline & & C8H18-01 & 0 & 19 & $1.22 \mathrm{E}-07$ & $1.90 \mathrm{E}+01$ \\
\hline \multirow[t]{3}{*}{16} & 50 & ETHANOL & 0.95 & 0 & $3.06 \mathrm{E}-32$ & 0.95 \\
\hline & & WATER & 0.05 & 0 & 0.03725759 & $1.27 \mathrm{E}-02$ \\
\hline & & C8H18-01 & 0 & 47.5 & $1.19 \mathrm{E}-07$ & $4.75 \mathrm{E}+01$ \\
\hline
\end{tabular}


Table SM-2: Raw stream data for temperature analysis

\begin{tabular}{|c|c|c|c|c|c|c|}
\hline Blending Ratio & Temperature $(\mathrm{C})$ & component & $\begin{array}{c}\text { Aqueous } \\
\text { feed }\end{array}$ & Fuel feed & $\begin{array}{c}\text { Fuel } \\
\text { product }\end{array}$ & $\begin{array}{c}\text { Aqueous } \\
\text { product }\end{array}$ \\
\hline \multirow[t]{3}{*}{6} & -25 & ETHANOL & 0.95 & 0 & 0.4190248 & 0.5309752 \\
\hline & & WATER & 0.05 & 0 & 0.0016023 & 0.0483977 \\
\hline & & C8H18-01 & 0 & 5.6999999 & 5.520788 & 0.1792119 \\
\hline \multirow[t]{3}{*}{6} & -15 & ETHANOL & 0.95 & 0 & 0.4967557 & 0.4532443 \\
\hline & & WATER & 0.05 & 0 & 0.0025704 & 0.0474296 \\
\hline & & C8H18-01 & 0 & 5.6999999 & 5.5655271 & 0.1344729 \\
\hline \multirow[t]{3}{*}{6} & 0 & ETHANOL & 0.95 & 0 & 0.6276873 & 0.3223127 \\
\hline & & WATER & 0.05 & 0 & 0.0048515 & 0.0451485 \\
\hline & & C8H18-01 & 0 & 5.6999999 & 5.6314679 & 0.0685321 \\
\hline \multirow[t]{3}{*}{6} & 12 & ETHANOL & 0.95 & 0 & 0.7365422 & 0.2134578 \\
\hline & & WATER & 0.05 & 0 & 0.007564 & 0.042436 \\
\hline & & C8H18-01 & 0 & 5.6999999 & 5.6724206 & 0.0275793 \\
\hline \multirow[t]{3}{*}{6} & 20 & ETHANOL & 0.95 & 0 & 0.8038479 & 0.1461521 \\
\hline & & WATER & 0.05 & 0 & 0.0098012 & 0.0401988 \\
\hline & & C8H18-01 & 0 & 5.6999999 & 5.6890796 & 0.0109203 \\
\hline \multirow[t]{3}{*}{6} & 25 & ETHANOL & 0.95 & 0 & 0.8394889 & 0.1105111 \\
\hline & & WATER & 0.05 & 0 & 0.0113285 & 0.0386715 \\
\hline & & C8H18-01 & 0 & 5.7 & 5.6947371 & 0.0052629 \\
\hline \multirow[t]{3}{*}{6} & 30 & ETHANOL & 0.95 & 0 & 0.8699285 & 0.0800715 \\
\hline & & WATER & 0.05 & 0 & 0.0128964 & 0.0371036 \\
\hline & & C8H18-01 & 0 & 5.6999999 & 5.6978484 & 0.0021516 \\
\hline \multirow[t]{3}{*}{6} & 40 & ETHANOL & 0.95 & 0 & 0.8940509 & 0.0559491 \\
\hline & & WATER & 0.05 & 0 & 0.0285357 & 0.0214643 \\
\hline & & C8H18-01 & 0 & 5.6999999 & 5.6976252 & 0.0023747 \\
\hline \multirow[t]{3}{*}{6} & 60 & ETHANOL & 0.95 & 0 & 0.9145821 & 0.0354179 \\
\hline & & WATER & 0.05 & 0 & 0.0314976 & 0.0185024 \\
\hline & & C8H18-01 & 0 & 5.6999999 & 5.6991359 & 0.0008641 \\
\hline \multirow[t]{3}{*}{8} & -25 & ETHANOL & 0.95 & 0 & 0.5559554 & 0.3940446 \\
\hline & & WATER & 0.05 & 0 & 0.0021392 & 0.0478608 \\
\hline & & C8H18-01 & 0 & 7.6 & 7.5055715 & 0.0944285 \\
\hline \multirow[t]{3}{*}{8} & -15 & ETHANOL & 0.95 & 0 & 0.6505145 & 0.2994855 \\
\hline & & WATER & 0.05 & 0 & 0.0034015 & 0.0465985 \\
\hline & & C8H18-01 & 0 & 7.6 & 7.5477522 & 0.0522478 \\
\hline \multirow[t]{3}{*}{8} & 0 & ETHANOL & 0.95 & 0 & 0.7897128 & 0.1602872 \\
\hline & & WATER & 0.05 & 0 & 0.0062035 & 0.0437965 \\
\hline & & C8H18-01 & 0 & 7.6 & 7.5887256 & 0.0112744 \\
\hline \multirow[t]{3}{*}{8} & 12 & ETHANOL & 0.95 & 0 & 0.8735214 & 0.0764787 \\
\hline & & WATER & 0.05 & 0 & 0.0090869 & 0.0409131 \\
\hline & & C8H18-01 & 0 & 7.6 & 7.598635 & 0.001365 \\
\hline \multirow[t]{3}{*}{8} & 20 & ETHANOL & 0.95 & 0 & 0.9077754 & 0.0422246 \\
\hline & & WATER & 0.05 & 0 & 0.0111398 & 0.0388602 \\
\hline & & C8H18-01 & 0 & 7.6 & 7.599785 & 0.000215 \\
\hline
\end{tabular}




\begin{tabular}{|c|c|c|c|c|c|c|}
\hline 8 & 25 & ETHANOL & 0.95 & 0 & 0.9210141 & 0.0289859 \\
\hline & & WATER & 0.05 & 0 & 0.0124134 & 0.0375866 \\
\hline & & C8H18-01 & 0 & 7.6 & 7.5999328 & $6.72 \mathrm{E}-05$ \\
\hline 8 & 30 & ETHANOL & 0.95 & 0 & 0.9297515 & 0.0202485 \\
\hline & & WATER & 0.05 & 0 & 0.0136723 & 0.0363277 \\
\hline & & C8H18-01 & 0 & 7.6 & 7.5999763 & $2.37 \mathrm{E}-05$ \\
\hline 8 & 40 & ETHANOL & 0.95 & 0 & 0.9396101 & 0.0103899 \\
\hline & & WATER & 0.05 & 0 & 0.016161 & 0.033839 \\
\hline 8 & 60 & C8H18-01 & 0 & 7.6 & 7.5999953 & $4.68 \mathrm{E}-06$ \\
\hline & & ETHANOL & 0.95 & 0 & 0.9463511 & 0.0036489 \\
\hline & & WATER & 0.05 & 0 & 0.0211908 & 0.0288092 \\
\hline & & C8H18-01 & 0 & 7.6 & 7.599999 & $1.05 \mathrm{E}-06$ \\
\hline
\end{tabular}

Table SM-3: Raw stream data for temperature swing process with temperature intervals of $55^{\circ}$ and $25^{\circ}$

\begin{tabular}{|c|c|c|c|c|c|c|c|}
\hline $\begin{array}{c}\text { Blending } \\
\text { Ratio: }\end{array}$ & & aqueous feed & fuel feed & $\begin{array}{c}\text { fuel after 1st } \\
\text { decanting }\end{array}$ & fuel out & $\begin{array}{l}\text { aqueous from } \\
1 \text { st decanting }\end{array}$ & $\begin{array}{l}\text { aqueous } \\
\text { product }\end{array}$ \\
\hline \multirow[t]{3}{*}{4} & ETHANOL & 0.95 & 0 & 0.679523 & 0.578702 & 0.270477 & 0.10076694 \\
\hline & WATER & 0.05 & 0 & 0.015986 & 0.008428 & 0.034014 & 0.00755131 \\
\hline & C8H18-01 & 0 & 3.8 & 3.712179 & 3.658681 & 0.087821 & 0.05348021 \\
\hline \multirow[t]{3}{*}{8} & ETHANOL & 0.95 & 0 & 0.858953 & 0.822078 & 0.091047 & 0.03687185 \\
\hline & WATER & 0.05 & 0 & 0.018668 & 0.011737 & 0.031332 & 0.00693027 \\
\hline & C8H18-01 & 0 & 7.6 & 7.594707 & 7.589125 & 0.005293 & 0.00558184 \\
\hline \multirow[t]{3}{*}{10} & ETHANOL & 0.95 & 0 & 0.888428 & 0.864938 & 0.061572 & 0.02348979 \\
\hline & WATER & 0.05 & 0 & 0.018696 & 0.012076 & 0.031304 & 0.0066204 \\
\hline & C8H18-01 & 0 & 9.5 & 9.498419 & 9.496681 & 0.001581 & 0.00173803 \\
\hline \multirow[t]{3}{*}{15} & ETHANOL & 0.95 & 0 & 0.919249 & 0.908518 & 0.030751 & 0.01073129 \\
\hline & WATER & 0.05 & 0 & 0.018367 & 0.012064 & 0.031633 & 0.00630225 \\
\hline & C8H18-01 & 0 & 14.25 & 14.24984 & 14.24967 & 0.000159 & 0.00016754 \\
\hline \multirow[t]{3}{*}{50} & ETHANOL & 0.95 & 0 & 0.944294 & 0.941977 & 0.005706 & 0.00231684 \\
\hline & WATER & 0.05 & 0 & 0.020792 & 0.012915 & 0.029208 & 0.00787621 \\
\hline & C8H18-01 & 0 & 47.5 & 47.5 & 47.5 & $1.98 \mathrm{E}-06$ & $8.09 \mathrm{E}-07$ \\
\hline
\end{tabular}

Table SM-4: Raw stream data for temperature swing process with temperature intervals of $55^{\circ}, 40^{\circ}$ and $25^{\circ}$

\begin{tabular}{|c|c|c|c|c|c|c|c|c|c|}
\hline $\begin{array}{c}\text { Blending } \\
\text { Ratio }\end{array}$ & & $\begin{array}{c}\text { aqueous } \\
\text { feed }\end{array}$ & fuel feed & $\begin{array}{c}\text { fuel after 1st } \\
\text { decanting }\end{array}$ & $\begin{array}{c}\text { fuel after 2nd } \\
\text { decanting }\end{array}$ & fuel out & $\begin{array}{c}\text { aqueous } \\
\text { from 1st } \\
\text { decanting }\end{array}$ & $\begin{array}{c}\text { aqueous from } \\
\text { 2nd decanting }\end{array}$ & $\begin{array}{c}\text { aqueous } \\
\text { product }\end{array}$ \\
\hline 4 & ETHANOL & 0.95 & 0 & 0.65339398 & 0.62898571 & 0.58324458 & 0.29660601 & 0.02440827 & 0.04574113 \\
\hline & WATER & 0.05 & 0 & 0.01432248 & $1.19 \mathrm{E}-02$ & 0.00849744 & 0.03567751 & $2.44 \mathrm{E}-03$ & 0.00338983 \\
\hline & C8H18-01 & 0 & 3.8 & 3.70022923 & $3.69 \mathrm{E}+00$ & 3.66566385 & 0.09977082 & $1.00 \mathrm{E}-02$ & 0.02456676 \\
\hline & & & & & & & & & \\
\hline
\end{tabular}




\begin{tabular}{|c|c|c|c|c|c|c|c|c|c|}
\hline 8 & ETHANOL & 0.95 & 0 & 0.85895266 & $8.45 \mathrm{E}-01$ & 0.82752609 & 0.09104732 & $1.35 \mathrm{E}-02$ & 0.01791047 \\
\hline & WATER & 0.05 & $0.00 \mathrm{E}+00$ & $1.87 \mathrm{E}-02$ & $1.51 \mathrm{E}-02$ & $1.18 \mathrm{E}-02$ & $3.13 \mathrm{E}-02$ & 3.53E-03 & 0.00331332 \\
\hline & C8H18-01 & 0 & $7.60 \mathrm{E}+00$ & $7.59 \mathrm{E}+00$ & $7.59 \mathrm{E}+00$ & $7.59 \mathrm{E}+00$ & $5.29 \mathrm{E}-03$ & $1.23 \mathrm{E}-03$ & 0.00278303 \\
\hline \multirow[t]{3}{*}{10} & ETHANOL & 0.95 & 0 & 0.88842789 & 0.87966044 & 0.86836102 & 0.0615721 & 0.00876744 & 0.01129942 \\
\hline & WATER & 0.05 & 0 & 0.01869603 & 0.01528629 & 0.01212973 & 0.03130396 & 0.00340974 & 0.00315655 \\
\hline & C8H18-01 & 0 & 9.5 & 9.49841866 & 9.49805172 & 9.49720146 & 0.00158137 & 0.00036695 & 0.00085027 \\
\hline \multirow[t]{3}{*}{15} & ETHANOL & 0.95 & 0 & 0.91924911 & 0.91512505 & 0.91003662 & 0.03075088 & 0.00412405 & 0.00508842 \\
\hline & WATER & 0.05 & 0 & 0.01836651 & 0.01506579 & 0.01208697 & 0.03163346 & 0.00330071 & 0.00297882 \\
\hline & C8H18-01 & 0 & 14.25 & 14.249841 & 14.2498068 & 14.2497268 & 0.00015925 & $3.42 \mathrm{E}-05$ & $8.00 \mathrm{E}-05$ \\
\hline \multirow[t]{3}{*}{50} & ETHANOL & 0.95 & 0 & 0.94429434 & 0.94329771 & 0.94223293 & 0.00570566 & 0.00099662 & 0.00106478 \\
\hline & WATER & 0.05 & 0 & 0.02079156 & 0.01653661 & 0.01291804 & 0.02920843 & 0.00425495 & 0.00361857 \\
\hline & C8H18-01 & 0 & 47.5 & 47.499998 & 47.4999977 & 47.4999973 & $1.98 \mathrm{E}-06$ & $3.24 \mathrm{E}-07$ & $3.72 \mathrm{E}-07$ \\
\hline
\end{tabular}




\title{
Gasoline pre-blending processes for efficient ethanol recovery: effects of process parameters and process modifications for improved performance
}

\begin{abstract}
With over twenty billion gallons of bio-ethanol produced annually, optimization of bio-ethanol production processes is a major priority for sustainability research. Recent research has made great strides toward improving the efficiency of bio-ethanol production through the development of gasoline pre-blending processes which use liquid-liquid phase separation to eliminate excess water with minimal energy input. This paper investigates the effects of process parameters on the performance and efficiency of this class of process, offering a design basis for engineers developing new processes along with a broader understanding of their potential performance and economic value. Also explored are a range of process modifications capable of improving process performance. It has been found that Blending Ratio and initial alcohol concentration are the key parameters in determining ethanol recovery, with the number of liquid-liquid contact stages and the temperature also being significant. It has also been shown that temperature-swing decanting can significantly improve alcohol recovery, reducing ethanol losses by as much as $33 \%$ in a typical gasoline pre-blending setup.
\end{abstract}

\section{Introduction}

Transportation accounts for over a quarter of all $\mathrm{CO}_{2}$ emissions, and is therefore a priority area for sustainability research and environmental legislation, with increasingly strict regulation on fuels. For this reason, many countries are adopting mandatory blending of biofuels. Biofuels and their blends with fossil fuels are seen as cleaner energy sources because they are partially produced from renewable feed-stocks, reducing net carbon emissions [1]-[3]. A blend in this context is prepared mixing two or more compatible petroleum products where at least one of them is a biofuel. The goal of most of this legislation is to minimize damage to the climate and to human health. Harmful combustion by-products can include $\mathrm{CO}$, NOx and PAHs (polycyclic aromatic hydrocarbons) unburned hydrocarbons and particulate matter [4], [5]. Such pollutants affect air quality, especially in urban contexts.

Different chemical substances have been tried as alternative for blending with gasoline. Ethanol is one of the most widely used renewable fuels for internal combustion engines [1], [5]. Considerable research has been conducted on the properties of ethanol as a fuel additive. For instance, [4] studied the characteristics and reactivity of soot particles from ethanolgasoline blends. [5] studied the blending of ethanol with gasoline in increasing ratios of ethanol $(10,20$ and $30 \% \mathrm{vol})$ and its effect in engine design. [6] studied the octane numbers of ethanol blends. [7] studied different combustion chamber geometries in spark ignition engines fueled with ethanol and gasoline blends, etc. Considerable research has also been conducted on the energy efficiency of the process of bio-ethanol production for use in fuel [2], [8], [9]. Particular focus has been placed on optimizing the process to improve its energy efficiency, thereby reducing its carbon footprint and increasing its profitability. 
A new approach to the process has been proposed, whereby ethanol is blended with gasoline without having first been fully purified, thereby exploiting liquid phase separation to conveniently eliminate the remainder of the water, as shown in Fig 1 [9], [10]. The mixture naturally splits into two phases which can be separated by means of one or more mixersettlers. In other words, the same phase split which makes water a problematic impurity in gasoline could be exploited to facilitate an energy-efficient separation; blending of water and gasoline results in the formation of two separate liquid phases without the addition of any separation energy. This process is called "gasoline pre-blending" because it does not need to fully eliminate the water prior to blending. If the design of the phase split is done correctly, the gasoline acquires the desired amount of ethanol, resulting in a suitable fuel mixture. According to this same author [9], [11], the overall process shown in Fig.1 results in more efficient separation of bioethanol from fermentation products, with significant energy and cost savings.

However, this class of processes has not yet been subject to detailed research or optimization, leaving considerable scope for improvement of the specific process shown in Fig 1, as well as the development of new processes using the concept of gasoline pre-blending.

This paper examines the effects of different variables: temperature, blending ratio (see section 2 ), number of mixer-settler units, water content in feed ethanol etc., on the performance and efficiency of gasoline pre-blending processes. This study serves to further explore the performance limits of this promising new class of processes, as well as to inform their design in an industrial context. It also examines process modifications that offer clear performance benefits, further improving the efficiency of ethanol production processes.

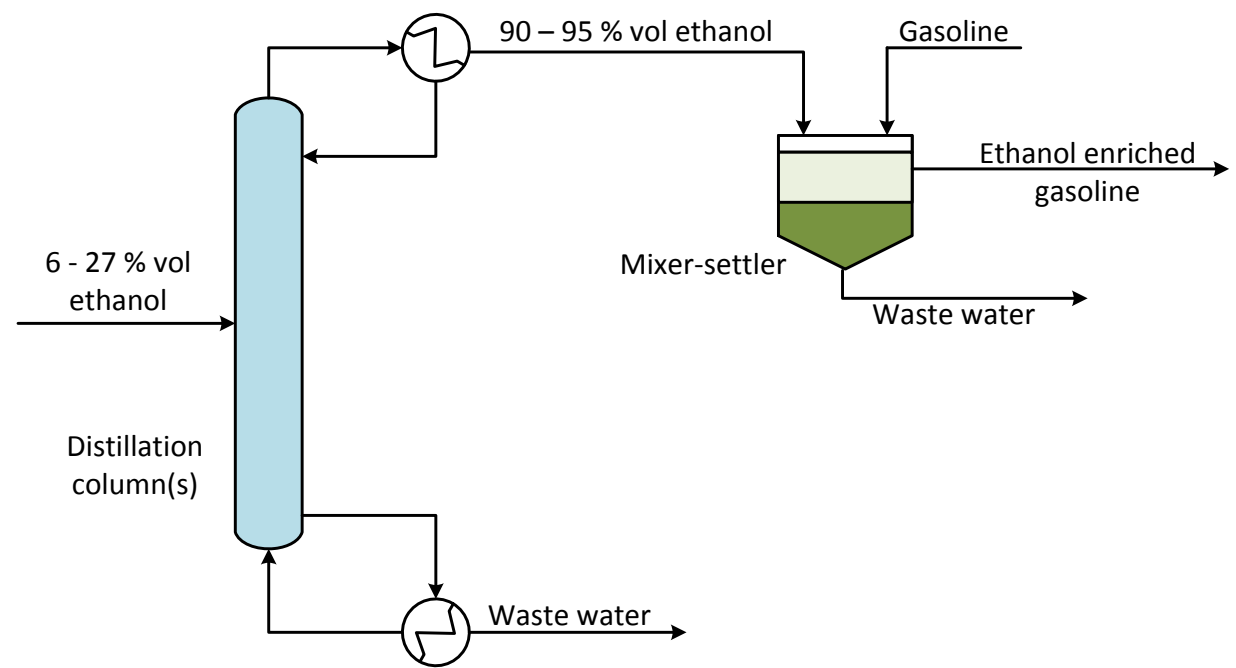

Fig 1. Overall process flowsheet for efficient bioethanol separation using ethanol pre-blending.

\section{Definitions and Methodology}

We need to define two parameters that will be used frequently in this research: recovery and blending ratio. Recovery is the fraction of alcohol/s (in this research ethanol) from the feed aqueous stream that ends up in the fuel phase. Blending ratio (BR) is the volume of gasoline fed to the liquid-liquid extraction unit(s) divided by the volume of (pure) ethanol in the aqueous 
stream fed to the same unit(s). The blending ratio must be selected based on the desired ethanol content in the fuel product and it can be more or less determined as soon as a product specification is selected which depends on the country. At present, the US legislations predominantly uses a $10 \%$ in volume blend of ethanol in gasoline. In South Africa, legislation mandates blends containing $2 \%$ ethanol. Hence, $10 \%$ and $2 \%$ blends are the targets in this paper firstly because they offer solutions for those two scenarios and secondly, because they offer a broad range of compositions, leading to results that can be considered qualitatively valid for compositions inside that range.

In order to be able to compare different situations, we would need abundant liquid-liquid equilibrium (LLE) data for the ternary mixture of water-ethanol-gasoline at different temperatures. Unfortunately, the exact composition of gasoline is variable since different brands have proprietary fuel additives and dyes. Furthermore, the composition of gasoline changes with time and location since technology and legislation evolve. As a result, no gasoline composition can be considered universal. This fact is expected to influence the phase equilibrium results and the outcomes of this research. We have circumvented this problem by choosing a reasonable stand-in for gasoline for the purpose of preliminary design: isooctane [9], [12] and achieve our goals with simulations in Aspen to model the phase equilibrium at different conditions. The results with isooctane can be extrapolated to particular gasoline blends since it provides a universal basis for design. The UNIQUAC model was selected for this purpose, using ASPEN's inbuilt parameters. The accuracy of this approach is somewhat debatable and the use of a fitted model is preferable where available but in the absence of gasoline-specific data at a range of temperatures, it becomes sensible to use the in-built modelling of a commercial package, which can be assumed to be sufficiently accurate for determining qualitative trends. For all these reasons, the results shown in this paper must be considered to be qualitative descriptions rather than exacting quantitative predictions. Actual process performance will vary considerably depending on a multitude of factors affecting fuel mix and stability. The results presented here are intended to serve as a baseline for preliminary design, from which a designer can extrapolate using the specific properties of the appropriate fuel mix for their context.

The different factors that we have tested are: blending ratio, temperature, number of mixingsettling units and water content on feed ethanol.

\section{Results}

The different results are grouped according to the main parameter analyzed. All numerical data obtained for this research are presented in detail in the supplementary data.

\subsection{Blending ratios}

The effects of blending ratio at atmospheric conditions and at $25^{\circ} \mathrm{C}$ with different number of units for mixing-settling (or stages) are presented in Fig.2. The ethanol content in the feed stream is $95 \%$ vol in all cases studied. Three different scenarios have been examined: 1-stage of mixing settling unit, 2-stages of mixing settling units and 16-stages. Fig. 2 shows two different parameters in the two $y$-axes plotted: recovery and volumetric percentage of ethanol in the fuel blend exit product. 


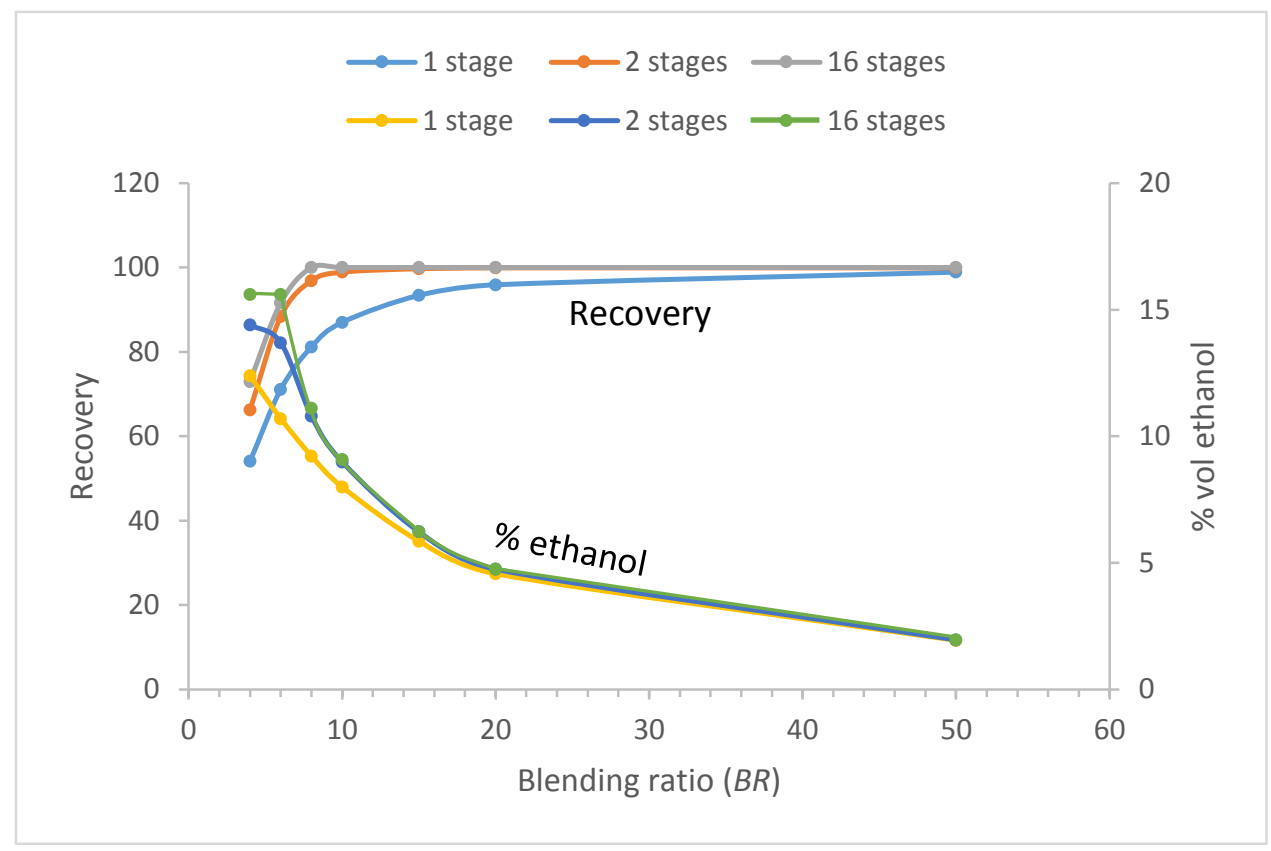

Fig 2. Effect of blending ratio in recovery and in the content of ethanol in the gasoline product at 25ㅇ.

Fig. 2 demonstrates the expected result that higher blending ratios (which will yield gasoline mixtures with low content of alcohol) result in higher recovery of ethanol. For the 16-stage process, complete recovery of ethanol occurs for all blending ratios 8 and above, indicating that for that case there is no benefit increasing the blending ratio above 8 , except perhaps for dealing with initial ethanol content lower than the $95 \%$ assumed here. A two-stage process with blending ratio in the 8-10 range offers the desirable ethanol content along with almost complete recovery. The multistage process with blending ratios in this range also achieves the desired composition, but with complete recovery of ethanol. This is quite likely the most desirable starting point for designing a process where the final product must be a $10 \%$ vol of ethanol.

It must be noted that the $2 \%$ ethanol blend required by South African law is easily obtained with a high recovery of ethanol. Even the single-stage process can achieve recovery of $98.9 \%$ for an ethanol content of $1.94 \%$. The 2 -stage process offers higher recoveries, approaching complete recovery for high blending ratios.

This has several implications for this process in the South African context. Firstly, a two-stage process will likely be adequate, giving designers the option of minimizing process complexity and capital cost while still achieving good process performance. Secondly, the multi-stage process so easily accomplishes what is necessary that it can be inferred that it may be possible to achieve a satisfactory performance when beginning with an ethanol mixture more dilute than the $95 \%$ studied here. This possibility is examined in section 3.4 .

\subsection{Temperature}

Temperature can be expected to have a profound impact on phase equilibrium and consequently on process performance. From section 3.1, we conclude that it seems reasonable to concentrate our research on a process with only 2 stages of mixer-settlers to obtain a good ethanol recovery for most blending ratios. Therefore, the basic flowsheet for the remainder of this paper is the one depicted in Fig. 3 with small variations that we shall see. 


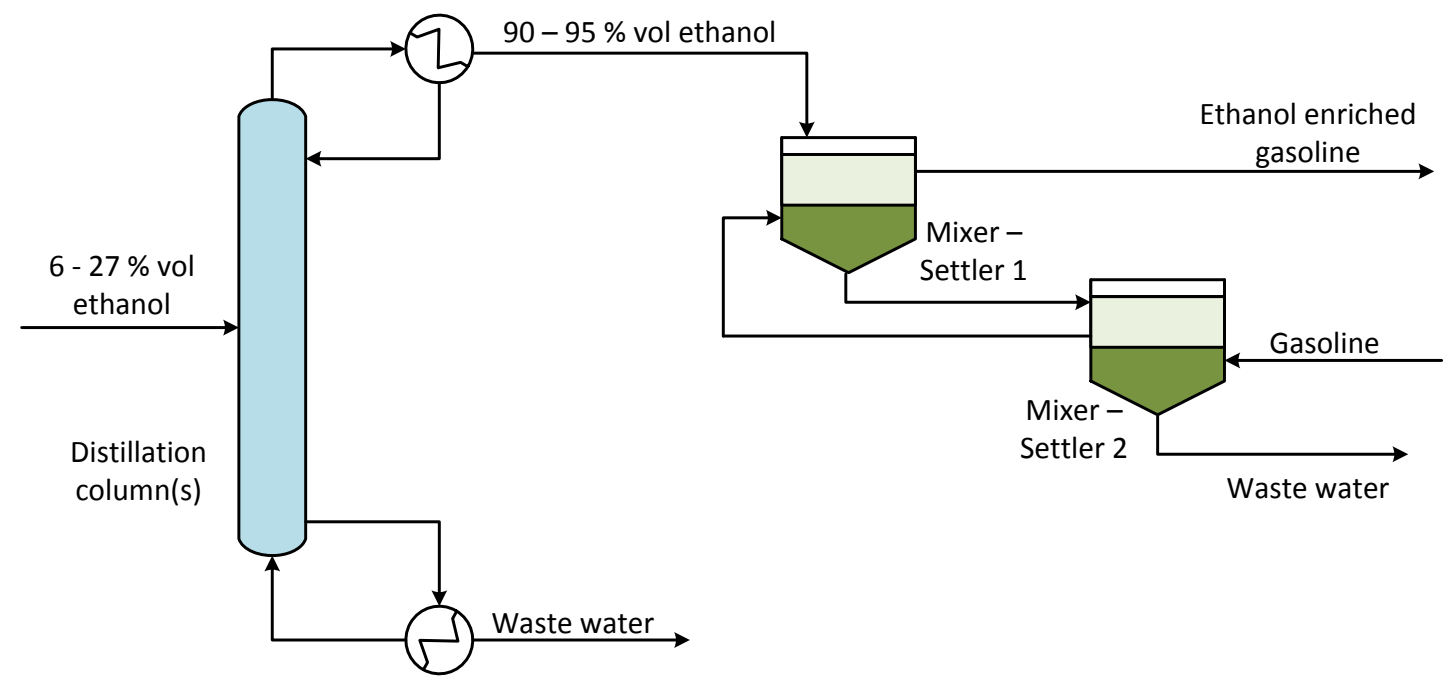

Fig. 3. Flowsheet with 2 stages of mixing-settling for enriching gasoline with alcohol from fermentation.

Also, from the results shown in section 3.1 we will study temperature effect for a $B R$ (blending ratio) at around 8 . Therefore, the effects of temperature on a two-stage blending process at $B R$ of 6 and 8 are simulated and the results shown in Fig.4. It is clear that temperature has a significant impact on the results. High-temperature phase-splits offer increased ethanol content and recovery but at the cost of higher water content that can reduce the stability of the blended gasoline. Stability in this context is understood as a possible phase-split (gasoline/water) happening inside the car tank. Lower temperature saturated mixtures have significantly lower water content than saturated mixtures at higher temperatures. This means that a mixture that is saturated at a high temperature will become unstable if the temperature is lowered, and that a mixture that is saturated at a low temperature (below ambient conditions) will be undersaturated and highly stable at ambient conditions.

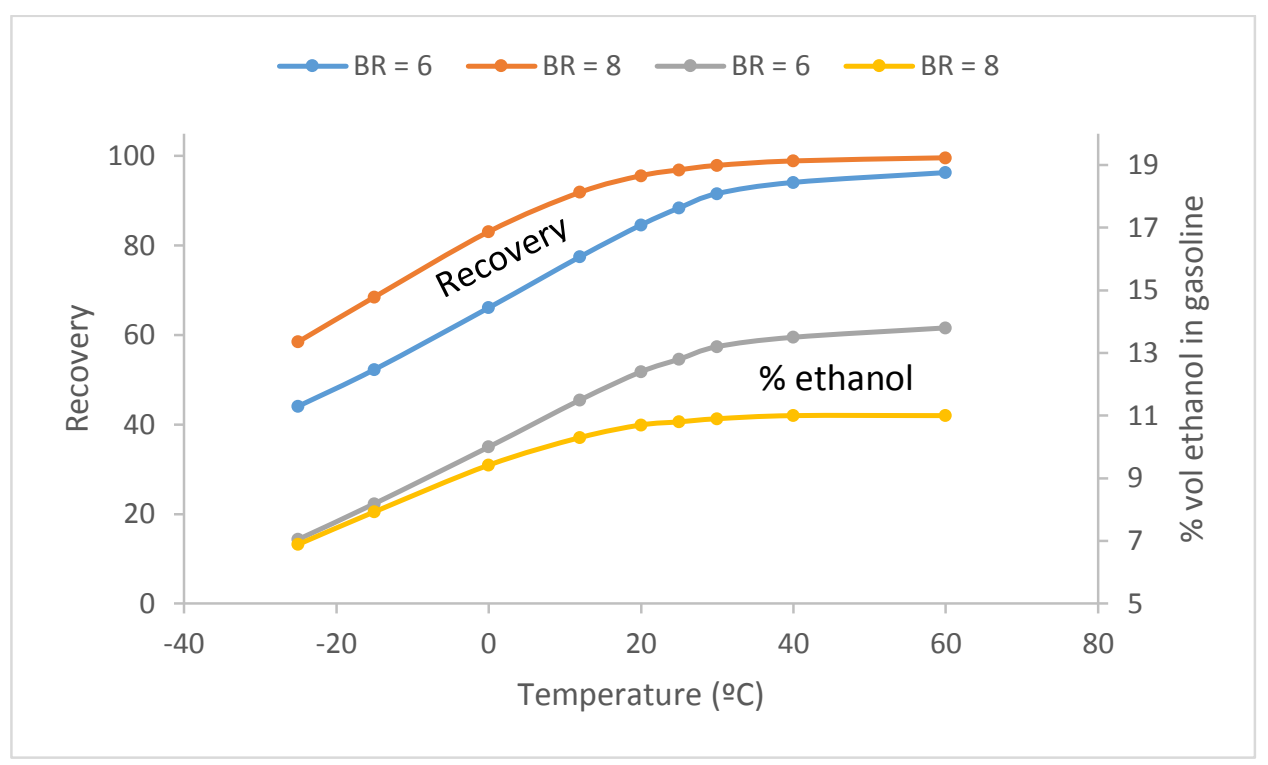




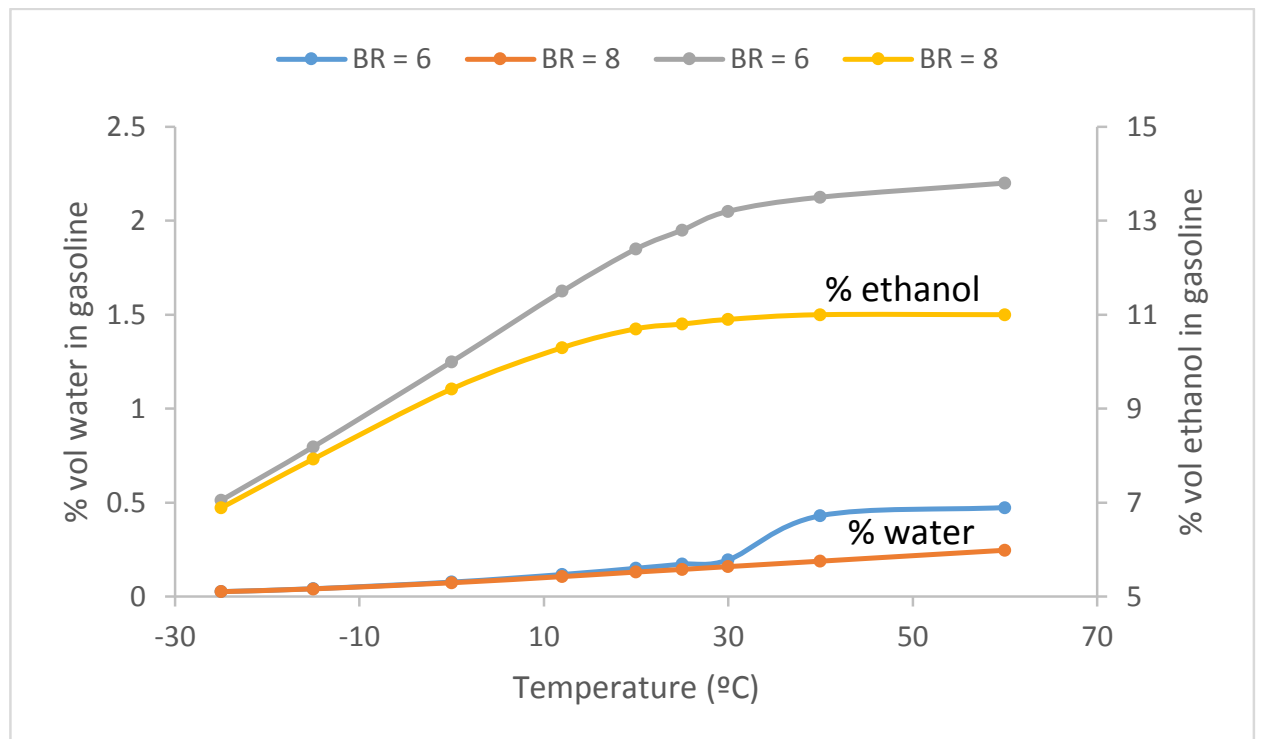

Fig 4. Effect of temperature on the recovery and percentages of ethanol (top) and water (bottom) in the gasoline product.

Low temperature phase-splits offer significantly more stable mixtures but this stability improvement is offset somewhat by the reduced ethanol content, which limits the possibility for stabilization through the blending of additional petrol. This, combined with the significant reduction in ethanol recovery and the general expense and impracticality of large-scale cryogenic processes suggests that these very low temperature processes are economically unfeasible.

Fig. 5 shows the effect of temperature on one particular tie line, chosen as an example. The 3 tie-lines correspond to the same heterogeneous mixture $(11.0 \%$ vol ethanol, $0.58 \%$ vol water, $88.4 \%$ vol isooctane). This information is taken from Fig.4 $(B R=8)$ and is fully documented in the Supplementary Material section. As the temperature increases, the content of ethanol in the aqueous phase decreases dramatically, whereas the ethanol content in the organic phase increases, although not much. It can be concluded that higher temperatures lead ethanol to favour the fuel phase more strongly, thereby improving the recovery of ethanol.

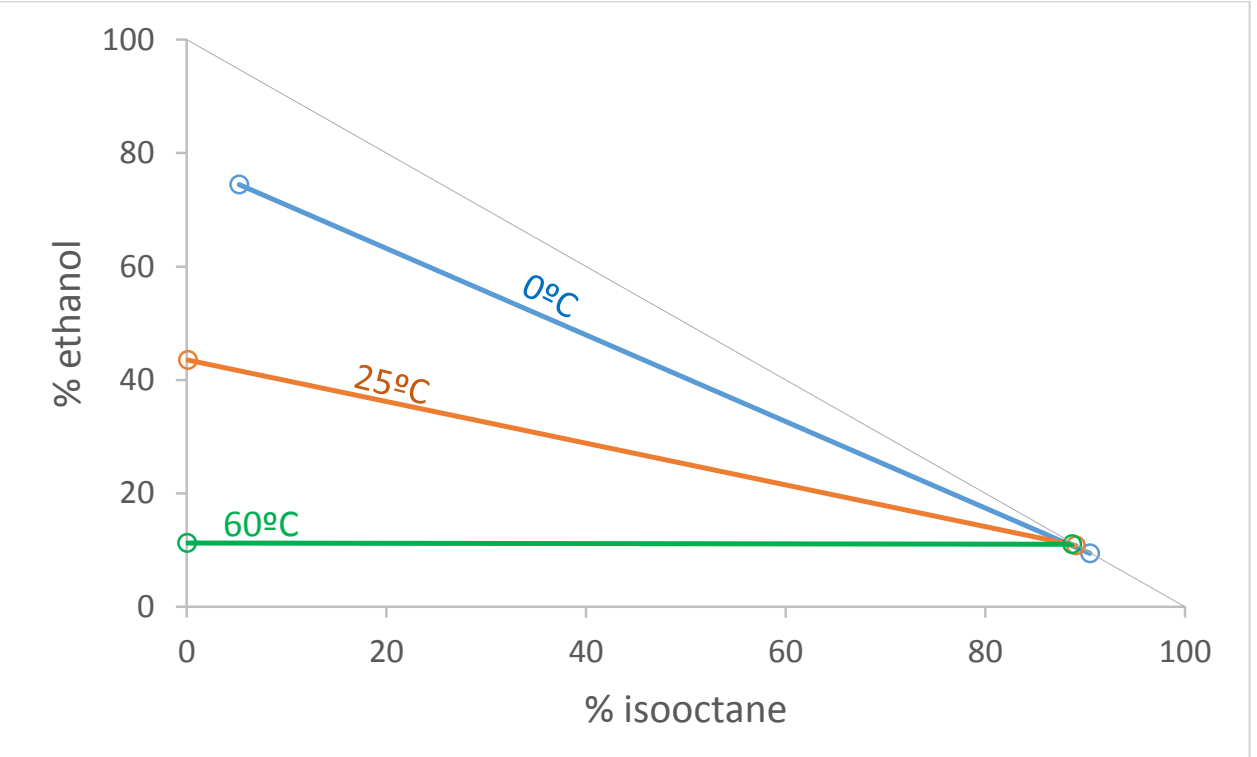

Fig 5. Effect of temperature on the tie line developed from the same heterogeneous mixture: $11.4 \%$ vol ethanol, $0.58 \%$ vol water, $88.4 \%$ vol isooctane 
One drawback of using higher-temperature phase splits is that they also result in a somewhat higher water content for the fuel phase. This means that a mixture that is saturated at a high temperature will be unstable at a lower temperature, and therefore not suitable for use as a fuel. Hence, a final decanting at a lower temperature would be needed in order to achieve a stable mixture. The specific details of a country's legislation will also impose different constraints on this final decanting. While some countries simply require a stable mixture, others specify a particular water content, regardless of stability, and those countries do not all specify the same thresholds. Hence, it is up to a designer to consider the particular context where a process will be implemented and adapt accordingly.

\subsection{Temperature Swing process}

From the results in the previous sections we conclude that a temperature-swing phase split is worth examining. This will imply that the initial liquid-liquid extraction takes place at high temperature (around $60^{\circ} \mathrm{C}$ ), resulting in a high recovery of ethanol. To eliminate the excess water and therefore improve stability for lower temperatures, this mixture could subsequently be decanted at one or two settlers at lower temperatures. This will result in adding one or two decanters to the flowsheet shown in Fig.3. The enhanced flowsheet is shown in Fig.6.

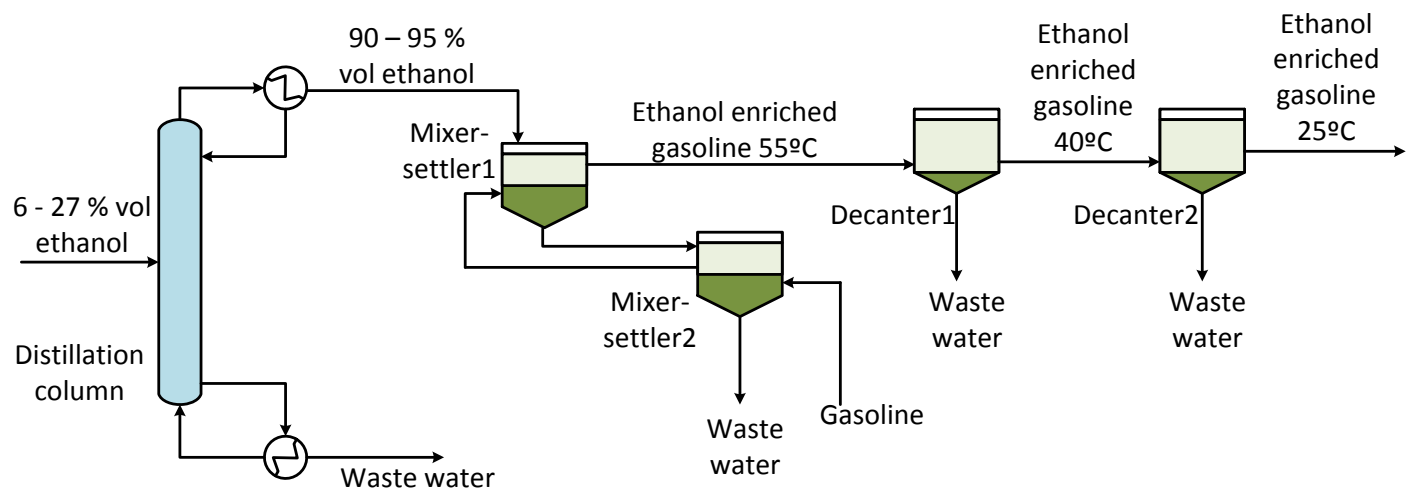

Fig 6. Flowsheet diagram where 2 extra decanters have been added to Fig.3.

In Fig. 6 it can be seen that blending occurs at high temperature. This is relatively easy to achieve since the overhead stream from the distillation column will be at high temperature and gasoline can be preheated with residual heat from the reboiler. The heterogeneous mixtures contain a small amount of water, because the ethanol is provided with relatively high purity. For this reason, the split aqueous phase cannot take with it much ethanol, despite that the tie lines reveal that water solubilizes ethanol better than isooctane.

The experiments conducted in this section assess the temperature swing proposed in Fig.6. The intention is to obtain a hydrocarbon product of the same stability as the one obtained at ambient temperature according to the flowsheet shown in Fig.3, and hopefully with a higher recovery of ethanol. Fig. 7 and 8 offer the corresponding results of the simulation in Aspen. These figures show that an initial 2-stage phase separation at $55^{\circ} \mathrm{C}$ followed by decanting at ambient temperature (" 2 stages +1 decanter") results in increased ethanol content and improved recovery when compared to the situation shown in Fig.3, particularly at low blending ratios. This result can be explained intuitively; as the temperature is lowered, water and gasoline become less and less miscible, so water is removed as temperature is dropped. Doing this at a series of 
staged temperatures instead of at a single low temperature minimizes the ethanol that is lost into the water phase as this occurs. The process situation depicted in Fig.6, i.e., "2-stages +2 decanters" with initial phase separation at $55^{\circ} \mathrm{C}$ and subsequent decanting at $40^{\circ} \mathrm{C}$ and $25^{\circ} \mathrm{C}$ results in not so much improvement if it is compared to the case of "2-stages +1 decanters" but it does improve if it is compared to the situation in Fig.3.

To illustrate the latest, let's consider the process with a blending ratio of 10 . the "2-stages" (Fig.3) results in a fuel product with $8 \%$ vol ethanol content where $13 \%$ of the feed ethanol is lost in the water phase, while the "2-stages +2 decanters" results in an ethanol content of $8.37 \%$ with $8.6 \%$ of ethanol lost in the water phase. This translates to a reduction of ethanol losses of about $34 \%$. All these results prove that it is worth considering a temperature swing process as a means of improving recovery in gasoline pre-blending processes.

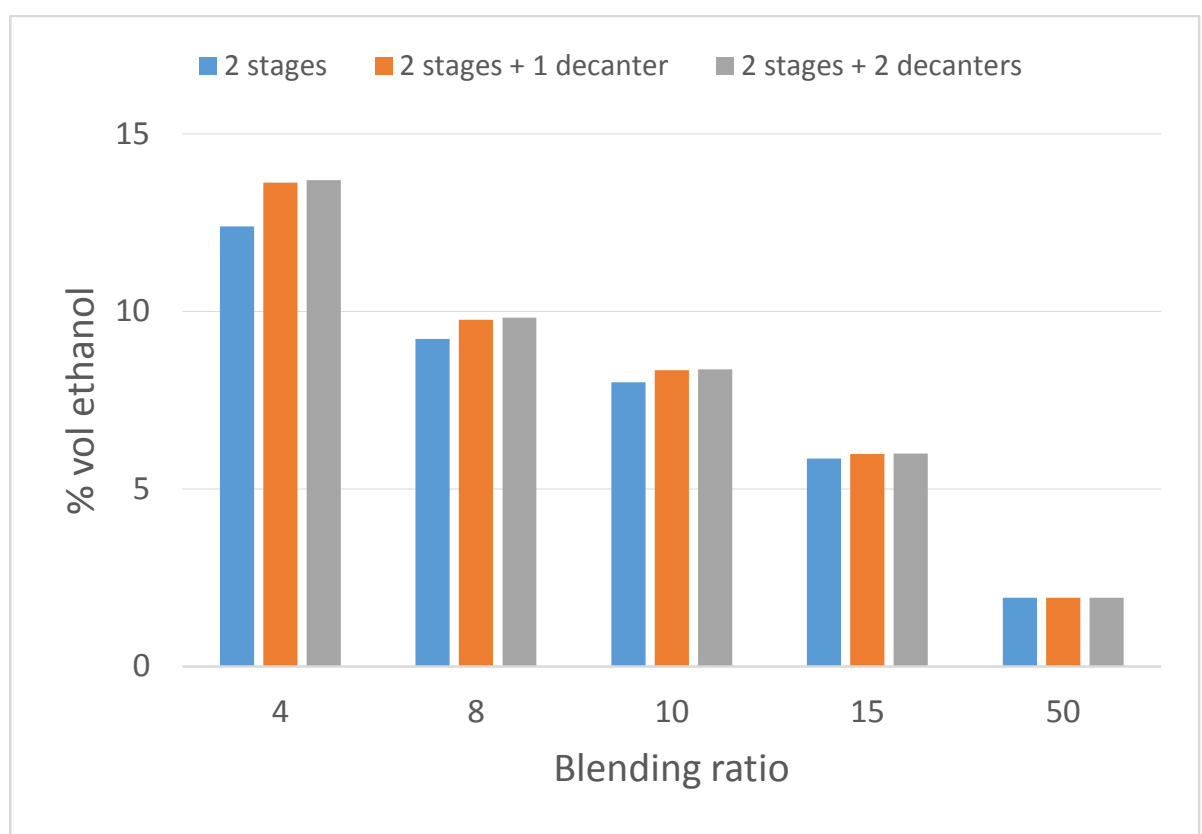

Fig 7. Effect of the temperature swing process on the volumetric percentage of ethanol at different blending ratios. "2 stages" corresponds to the situation depicted in Fig. 3 (both settlers at 25ㄷ). "2 stages + 1 decanter" corresponds to the situation in Fig. 6 but without decanter 1 (temperatures are 55ㅇ for the first and second mixer-settler and 25C for the decanter2). "2 stages +2 decanter" series corresponds to exactly Fig. 6. 


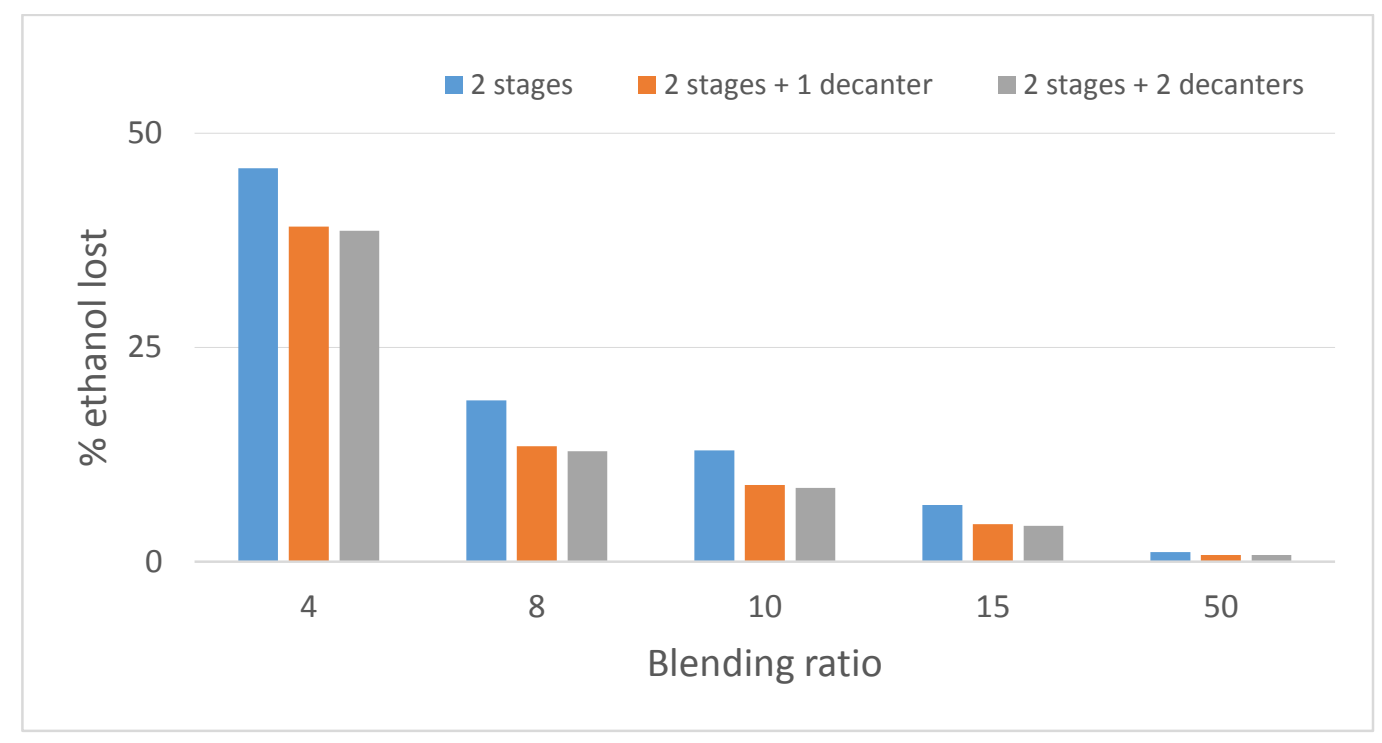

Fig 8. Effect of the temperature swing process on the \% of ethanol lost in the water phase (ethanol in aqueous stream / ethanol in feed stream $\times 100 \%$ ) at different blending ratios. "2 stages" corresponds to the situation depicted in Fig. 3 (both settlers at 25ㅇ) . "2 stages +1 decanter" corresponds to the situation in Fig. 6 but without decanter 1 (temperatures are 55ㅇ for the first and second mixer-settler and 25ㅇ for the decanter2). " 2 stages +2 decanter" series corresponds to exactly Fig.6.

The logical extreme of this approach is to decant in a batch process where the aqueous phase is removed as it forms while the temperature is gradually lowered. The final decanting step need not be at ambient conditions; it could be conducted at a lower temperature in order to achieve improved stability while offsetting the performance reductions of low temperature phase separation.

\subsection{The effect of the content of water in the ethanol feed stream}

In this section we consider the effect of the water content in the ethanol stream. The $2 \%$ ethanol mixture required by South African law can be easily reached with high recovery using just single (Fig.1) or double stage (Fig.3) liquid-liquid extraction. This simplifies the process equipment required, but also suggests that a more challenging extraction from a stream with larger amount of water could be achieved using a multi-stage approach like that depicted in Fig.6. Starting with an ethanol composition lower than $95 \%$ would reduce the costs associated with the primary separation step and is therefore worth investigating in this case. We have explored three different scenarios: (a) an ethanol feed stream containing $85 \%$ vol in ethanol assessed in a process shown in Fig. 3 at 25ㅇ; (b) an ethanol feed stream containing $50 \%$ vol in both, ethanol and water, also assessed in the process shown in Fig. 3 at $25{ }^{\circ} \mathrm{C}$ and (c) an ethanol feed stream containing $50 \%$ vol in both, ethanol and water, but assessed with the process shown in Fig.6. The results of this analysis is presented in Fig.10 and 11.

Fig. 10 and 11 show that with an initial ethanol content of $85 \%$, the process remains viable for the South African context, since near-total recovery of ethanol still occurs at a blending ratio of 50 while producing a fuel mixture with ethanol content close to the $2 \%$ required in SA. Purification to $85 \%$ can be presumed to be somewhat less costly than purifying to $95 \%$, so this result suggests another avenue of possible cost-saving and optimization. However, the lower ethanol content has a ruinous effect on the prospects of the process for the American or European contexts. With a starting ethanol content of $85 \%$, a two-stage process with a blending 
ratio of 4 recovers only $41.5 \%$ of ethanol, and doesn't even achieve $10 \%$ ethanol content. In other words, the more stringent requirements of the American/European context result in a process much more sensitive to starting ethanol content, whereas the South African context allows for a much more flexible process. In fact, beginning with an ethanol content of just $50 \%$ and using temperature swing decanting, a blending ratio of 40 results in a fuel mixture with ethanol content of $1.95 \%$, and ethanol recovery of $79.5 \%$.

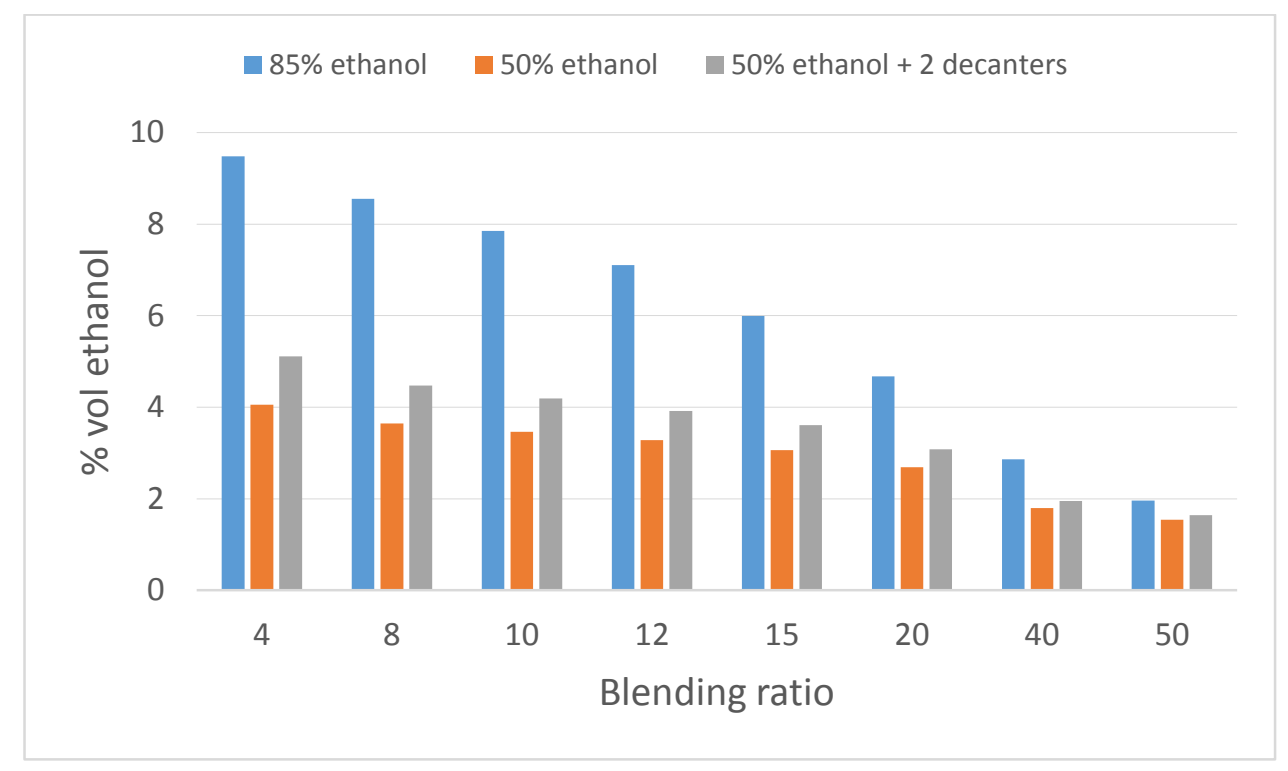

Fig 9. Effect of the amount of water in the feed ethanol stream for different BR on the \% of ethanol in the final product. Three different scenarios: (a) feed stream $85 \% \mathrm{vol}$ ethanol in a process shown in Fig.3 at 25C; (b) feed stream $50 \%$ vol ethanol in a process shown in Fig. 3 at 25ㄷ and (c) feed stream 50\% vol ethanol in a process shown in Fig. 6.

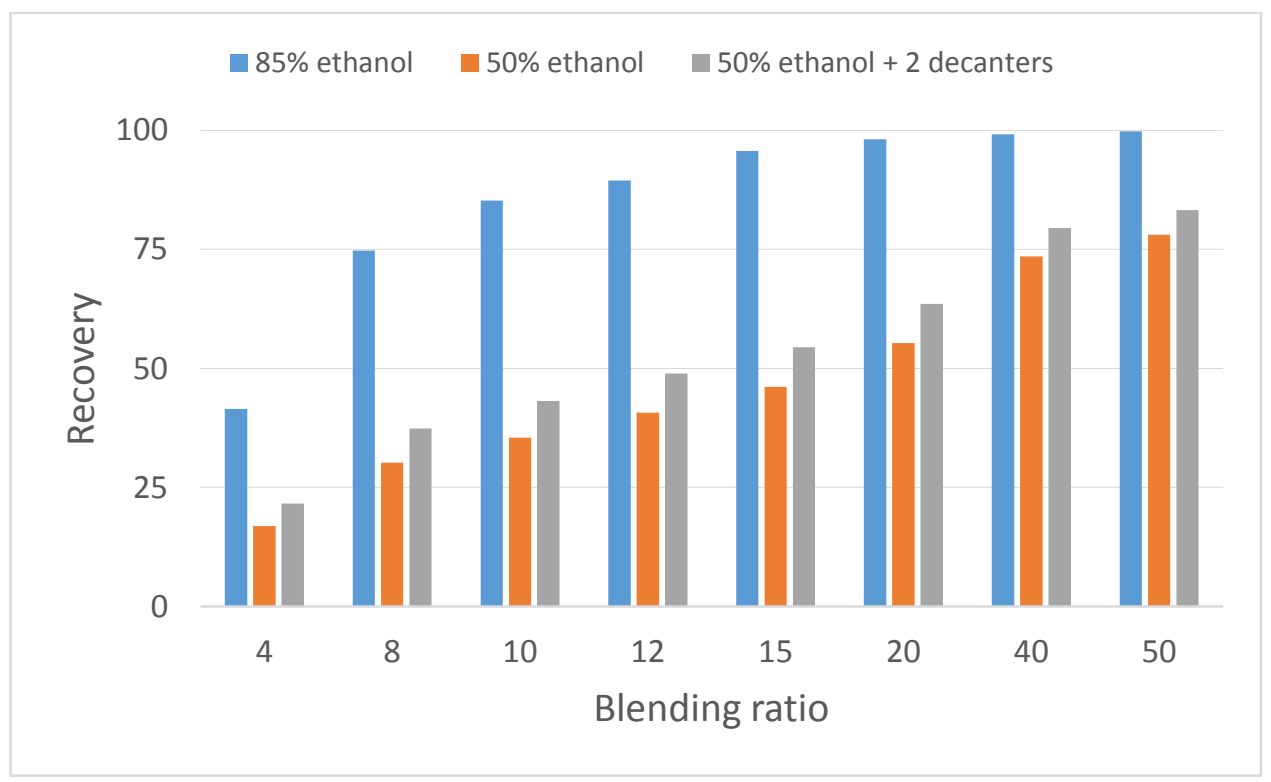

Fig 10. Effect of the amount of water in the feed ethanol stream for different BR on the recovery. Three different scenarios: (a) feed stream $85 \% \mathrm{vol}$ ethanol in a process shown in Fig. 3 at $25^{\circ} \mathrm{C}$; (b) feed stream $50 \%$ vol ethanol in a process shown in Fig. 3 at $25^{\circ} \mathrm{C}$ and (c) feed stream $50 \%$ vol ethanol in a process shown in Fig. 6.

Literature survey does not offer much by way of analysis of the energy requirements for distilling ethanol mixtures to this sort of composition, since it is not a step that is of particular interest in conventional processes to purify ethanol. However, it can be reasonably assumed that the 
energy requirements and capital cost investments required by such a process would be significantly below those involved in full purification, or even in purification to the azeotrope. It is up to designers to evaluate on a case-by-case basis whether or not the benefits of reduced separations costs are worth the reduced ethanol recovery, but this preliminary analysis indicates that it is a possibility worth considering.

\section{Conclusions}

In this research paper, the effects of design parameters have been examined in detail, yielding insights into the specific design decisions likely to optimize performance in any particular geographical context, and into the general thinking involved in developing and implementing phase-separation processes for bioethanol recovery, or for the recovery of other bio-fuels in similar processes.

Temperature, blending ratio and number of phase equilibrium stages have been identified as the main parameters affecting the performance of the phase separation process.

Higher temperatures result in higher ethanol content of the gasoline product and recovery, but stability is also linked to the temperature at which the final product is decanted. The temperature-swing decanting approach takes advantage of the improved ethanol recovery at higher temperatures without adversely affecting the stability of the final mixture. The step-wise decanting approach further improves process performance for the same reasons.

The blending ratio must be selected based on the desired ethanol content in the fuel product and is more or less determined as soon as a product specification is selected, excepting that there is some variation in the exact number insofar as other parameters affect the ethanol recovery and content to some degree.

The ideal number of stages, on the other hand, is highly contextual and will depend on economic considerations. The cost and process complexity involved in multi-stage processes are particularly undesirable if a high number of blending facilities are used at end-points on the fuel distribution network. A decentralised approach is ideal for limiting the financial impact of the corrosive effects of water, so this factor must be balanced against the economies of scale of central processing. In cases where a one- or two-stage process is able to achieve a desirable recovery and ethanol content, a decentralised approach becomes more viable.

In the South African context, the ideal approach is probably one where two-stage phaseseparation is carried out at a number of locations near the end-points of a fuel distribution network. Reaching the azeotrope in the initial separation is not necessary if the required ethanol content is $2 \%$, as in the South African context, and the most economical approach will likely be to reduce the cost of that initial separation by using a mixture with purity somewhat below the azeotrope.

The more stringent requirements of the US context places a strict constraint on the starting ethanol content; even with considerable process modification, processes beginning with reduced ethanol content cannot achieve adequate recovery of ethanol along with the $10 \%$ ethanol required in that context. The difficulty of achieving this high ethanol content also makes this process highly sensitive to any other factor affecting performance and it can thus be expected that in the US context, gasoline pre-blending processes must necessarily be somewhat over-designed in order to reliably achieve recovery targets. Hence, it is suggested that this be achieved through the use of multi-stage pre-blending processes. It has also been found in this paper that temperature step-down decanting can significantly improve ethanol recovery and should therefore be strongly advised for contexts where performance requirements are particularly stringent. 


\section{REFERENCES}

[1] A. DEMIRBAŞ, "Bioethanol from Cellulosic Materials: A Renewable Motor Fuel from Biomass," Energy Sources, vol. 27, no. 4, pp. 327-337, Feb. 2005.

[2] J. Goldemberg, "Ethanol for a Sustainable Energy Future," Science, vol. 315, no. 5813, pp. 808-810, Feb. 2007.

[3] Y. Lin and S. Tanaka, "Ethanol fermentation from biomass resources: current state and prospects," Appl. Microbiol. Biotechnol., vol. 69, no. 6, pp. 627-642, Feb. 2006.

[4] G. D. J. Guerrero Peña, Y. A. Hammid, A. Raj, S. Stephen, T. Anjana, and V. Balasubramanian, "On the characteristics and reactivity of soot particles from ethanolgasoline and 2,5-dimethylfuran-gasoline blends," Fuel, vol. 222, pp. 42-55, Jun. 2018.

[5] P. lodice, G. Langella, and A. Amoresano, "Ethanol in gasoline fuel blends: Effect on fuel consumption and engine out emissions of SI engines in cold operating conditions," Appl. Therm. Eng., vol. 130, Nov. 2017.

[6] J. Badra, A. S. AlRamadan, and M. Sarathy, "Optimization of the octane response of gasoline/ethanol blends," Jul. 2017.

[7] H. Al-Rawashdeh, "Impact of changing combustion chamber geometry on emissions, and combustion characteristics of a single cylinder SI (spark ignition) engine fueled with ethanol/gasoline blends," Jun. 2018.

[8] A. E. Farrell, R. J. Plevin, B. T. Turner, A. D. Jones, M. O'Hare, and D. M. Kammen, "Ethanol can contribute to energy and environmental goals," Science, vol. 311, no. 5760, pp. 506-508, Jan. 2006.

[9] N. T. Stacey, A. Hadjitheodorou, and D. Glasser, "Gasoline Preblending for EnergyEfficient Bioethanol Recovery," Energy Fuels, vol. 30, no. 10, pp. 8286-8291, Oct. 2016.

[10] A. Singh and G. P. Rangaiah, "Review of Technological Advances in Bioethanol Recovery and Dehydration," Ind. Eng. Chem. Res., vol. 56, no. 18, pp. 5147-5163, May 2017.

[11] N. T. Stacey, "Alternatives to distillation: multi-membrane permeation and petrol preblending for bio-ethanol recovery," Thesis, 2016.

[12] M. Rahman, M. Asadullah, M. Rahman, M. Nabi, and M. Azad, "Extraction of Gasohol Grade Ethanol from Aqueous Solution using Gasoline as Solvent," Bangladesh J. Sci. Ind. Res., vol. 42, no. 3, Feb. 2008. 